\title{
CAMA
}

Centre for Applied Macroeconomic Analysis

\section{The Macroeconomic Effects of Commodity Price Uncertainty}

\section{CAMA Working Paper 9/2021 January 2021}

\section{Trung Duc Tran}

School of Economics - University of Sydney

Centre for Applied Macroeconomic Analysis, ANU

\section{Abstract}

This paper studies the macroeconomic effects of commodity price uncertainty (CPU) shocks. Using Australia as a case study, an econometric-based CPU index is proposed to reveal that Australia has experienced an unprecedented increase in uncertainty from the commodity market recently. Evidence from a VAR model shows that CPU shocks have a larger recessionary impact than other relevant uncertainty shocks such as financial, economic and trade policy uncertainty. The empirical results are then interpreted in a non-linear multisector DSGE model of the Australian economy by estimating key parameters in the DSGE model to match its responses to the VAR responses. CPU shocks in the DSGE model, via foreign commodity export demand with price rigidity, trigger a precautionary response and cause a decline in real economic activity. 


\title{
Keywords
}

Commodity Price Uncertainty, Small Open Economy, VAR-DSGE

\author{
JEL Classification
}

C32, F41, E32

Address for correspondence:

(E) cama.admin@anu.edu.au

ISSN 2206-0332

The Centre for Applied Macroeconomic Analysis in the Crawford School of Public Policy has been established to build strong links between professional macroeconomists. It provides a forum for quality macroeconomic research and discussion of policy issues between academia, government and the private sector.

The Crawford School of Public Policy is the Australian National University's public policy school, serving and influencing Australia, Asia and the Pacific through advanced policy research, graduate and executive education, and policy impact. 


\title{
The Macroeconomic Effects of Commodity Price Uncertainty
}

\author{
Trung Duc Tran*
}

This version: December 2020

First version: December 2018

\begin{abstract}
This paper studies the macroeconomic effects of commodity price uncertainty (CPU) shocks. Using Australia as a case study, an econometric-based CPU index is proposed to reveal that Australia has experienced an unprecedented increase in uncertainty from the commodity market recently. Evidence from a VAR model shows that CPU shocks have a larger recessionary impact than other relevant uncertainty shocks such as financial, economic and trade policy uncertainty. The empirical results are then interpreted in a non-linear multisector DSGE model of the Australian economy by estimating key parameters in the DSGE model to match its responses to the VAR responses. CPU shocks in the DSGE model, via foreign commodity export demand with price rigidity, trigger a precautionary response and cause a decline in real economic activity.
\end{abstract}

JEL-Classification: C32, F41, E32

Keywords: Commodity Price Uncertainty, Small Open Economy, VAR-DSGE

${ }^{*}$ School of Economics - University of Sydney. Email: trungduc.tran@sydney.edu.au 


\section{Introduction}

Commodity prices are becoming more volatile. Despite significant falls during the global financial crisis, the past decade has witnessed fluctuations in the prices of many commodities, fueled by ongoing economic development in Asia, global trade tensions and uncertain global economic prospects. The size of these price changes has resulted in an unprecedented level of uncertainty surrounding the commodity market and thus prompts the need for an investigation of the macroeconomic effects of commodity price uncertainty.

This paper fills the literature gap by providing a comprehensive study on the macroeconomic effects of commodity price uncertainty in a small open economy setting. It does so by first developing a measure of commodity price uncertainty, then estimating the macroeconomic effects, and last interpreting the such effects through the lens of a small open economy structural model. The paper focuses on Australia due to its increasing reliance on commodity exports. In the past decade, commodity exports have made up more than half of Australia's total exports of goods and services. Australia is thus a compelling country to study the possible macroeconomic effects of commodity price uncertainty shocks. The approach in this paper is of course of interest to other commodity exporting economies.

First, a time-varying commodity price uncertainty index (CPU) is constructed to characterize the evolution of uncertainty surrounding the commodity market. The index is computed as the conditional volatility of the unpredictable component of a number of commodity prices in a forecasting regression in the spirit of Jurado et al. (2015), and is an extension of the oil price uncertainty index (OPU) (see Cross et al. (2019) and Nguyen et al. (2019)). ${ }^{1}$ This approach is able to account for a large number of commodities. Furthermore, unlike commonly used volatil-

\footnotetext{
${ }^{1}$ An earlier study by Dehn (2000) proposes a GARCH-based measure to capture commodity market uncertainty. The literature, however, usually focuses more on oil price uncertainty historically and relies on model-based measures, for example, the CBOEs Oil Price Volatility index (OVX), GARCH (Elder and Serletis (2010)) or SV
} (Jo (2014)). 
ity indicators, this uncertainty definition captures the fact what matters for economic decision making is not whether the real price of oil has become more or less variable, but rather whether it has become more or less predictable, i.e. less or more uncertain. The CPU index shows that Australia has experienced an unprecedented increase in uncertainty from the commodity market recently.

Second, a VAR model for a small open economy in the tradition of Dungey and Pagan (2000) is estimated and is incorporated with the measure of commodity price uncertainty proposed in the first step. The small open economy model assumption allows the investigation of whether an exogenous commodity market uncertainty shock is an important source of business cycle fluctuations. In this setting, commodity uncertainty is modeled along with a number of macroeconomic indicators including commodity prices, output, investment, consumption, hours worked, exports, imports, monetary policy rate, inflation and the real exchange rate. The VAR evidence reveals that the effects of commodity price uncertainty shocks on economic activity are recessionary. The recessionary effects are also quantitatively larger than other uncertainty shocks that might affect the Australian economy such as economic and trade policy uncertainty; financial uncertainty or U.S. macro uncertainty.

Last, the paper interprets the empirical evidence through the lens of a DSGE model. To this end, the DSGE model for the Australian economy in the spirit of Rees et al. (2016) is extended to incorporate commodity price uncertainty. Two key features of this approach are, first, it clearly distinguishes commodity price shocks and commodity price uncertainty shocks. Second, uncertainty shocks have a temporary impact on the commodity market and the overall economy. It is thus different from the work by Kulish and Rees (2017) who document the effect of a permanent increase in commodity price and commodity volatility in Australia. ${ }^{2}$ Structural parameters in the DSGE are then estimated to match the DSGE responses to those of the VAR.

\footnotetext{
${ }^{2}$ Other studies, for example, Hansen and Gross (2018) or Jääskelä and Smith (2013) focus exclusively on the transmission of commodity price shocks in Australia.
} 
It is found that the DSGE does well in matching the responses of real variables in the VAR. In the presence of price rigidity, a surprise increase in commodity price uncertainty triggers an economy-wide precautionary increase in markups and causes a decline in real economic activity. The transmission mechanism therefore corroborates the insights of Fernández-Villaverde et al. (2015), who suggest that a fiscal uncertainty shock depresses economic activity by inducing firms to raise markups.

The main body of this paper belongs to the broad literature which has investigated the role of uncertainty shock in an open economy context. ${ }^{3}$ The paper shares some similarities with Başkaya et al. (2013), Born and Pfeifer (2014), Caldara et al. (2020), Fernández-Villaverde et al. (2011), Garcıa Cicco et al. (2013), Gómez-González et al. (2013) and Pfeifer et al. (2012). Among many differences, this paper has two key distinctions with respect to these works, namely, (i) the nature by which an uncertainty shock is captured in the structural DSGE model; and (ii) the econometric framework that estimates uncertainty from the data. While this paper studies uncertainty faced by the commodity exporting sector, Başkaya et al. (2013) focus on oil uncertainty in an oil importing economy. Born and Pfeifer (2014) and Fernández-Villaverde et al. (2011) study the macroeconomic effects of world real interest rate uncertainty on Argentina, Brazil, Ecuador and Venezuela. Gómez-González et al. (2013) and Pfeifer et al. (2012), in contrast, model terms-of-trade uncertainty which is an aggregate shock. With respect to Garcıa Cicco et al. (2013), we both consider sector-specific uncertainty shocks in the commodity sector. Garcia Cicco et al. (2013), however, do not find contractionary responses of economic activity to higher commodity price uncertainty shocks. Caldara et al. (2020), on the other hand, focus on trade policy uncertainty in form of uncertainty about tariffs. The results are also corroborated by Baker et al. (2016), Crowley et al. (2018), Davis (2016), Handley (2014), Handley and Limão (2015), Handley and Limão (2017) or Steinberg (2019) who show the link between

\footnotetext{
${ }^{3}$ For recent development in the literature, see Bloom (2014), Castelnuovo et al. (2017), Castelnuovo (2019), and Fernández-Villaverde and Guerrón-Quintana (2020).
} 
policy uncertainty, trade and real economic activity.

The remainder of the paper is structured as follows. Section 2 describes the construction of the uncertainty index for the commodity market. Section 3 reports the VAR evidence. Section 4 presents the DSGE model and the solution. Section 5 discusses the main results. Section 6 concludes.

\section{Measuring Commodity Price Uncertainty}

This section computes uncertainty in the commodity market by using the one-period-ahead forecast error variance of commodity prices in a forecasting regression with stochastic volatility. The 1-period ahead uncertainty $C P U_{t}$, of commodity price series, $c p_{j t} \in C P_{t}=\left(c p_{1 t}, \ldots, c p_{N t}\right)$, is the conditional volatility of the un-forecastable component. That is:

$$
C P U_{j t}=\sqrt{E\left[\left(c p_{j t+1}-E\left[c p_{j t+1} \mid I_{t}\right]\right)^{2} \mid I_{t}\right]}
$$

where the expectation $E\left(. \mid I_{t}\right)$ is formed with respect to information available at time $t$ to economic agents. Uncertainty will thus be higher when today's expectation of the squared error in forecasting $c p_{j t+h}$ rises. The proper measurement of uncertainty requires removing the forecastable component $E\left[c p_{j t+h} \mid I_{t}\right]$ before computing conditional volatility. Failure to do so will lead to estimates that treat forecastable components as uncertainty components. Thus, uncertainty in a series is not the same as the conditional volatility of the raw series where no predictive information is taken into account. While this consideration is straightforward, this matters empirically as shown in Jurado et al. (2015) for the construction of the U.S. macro uncertainty index, and in Nguyen et al. (2019) or Cross et al. (2019) for the construction of the oil price uncertainty index.

An index of commodity price uncertainty of interest can be represented by a weightedaverage from a weighting vector, $w_{j}$, of each individual uncertainty of a given commodity at 
each date $t$ :

$$
C P U_{t}=w_{j} C P U_{j t}
$$

I consider 47 monthly standardised global commodity price series extracted from the IMF starting from 1994M01 to 2017M06. These individual price series belong to 5 major groups of commodity: Food, Beverage, Raw Agricultural, Fuel and Metal. To construct the one-periodahead commodity price uncertainty index, first, the conditional expectation in Equation (1) is estimated using by Equation (3) to make sure the forecast error is "purged" of the predictive content.

$$
c p_{j, t+1}=\Phi_{j}(L) c p_{j, t}+\Lambda_{i}(L) X_{j, t}+u_{j, t+1} e_{j, t+1} \quad \text { for } \quad j=1, \ldots, 47
$$

where $\Phi_{j}(L)$ and $\Lambda_{i}(L)$ are lag polynomials where the lag length is determined by AIC, and $X_{t}$ is a matrix of predictors which contain additional information that is considered robust in predicting and explaining commodity prices such as the commodity currency exchange rates, global economic activity, U.S uncertainty and the comovements in the commodity market.0 Chen et al. (2010) show that commodity-currency exchange rates including the Australian Dollar, Canadian Dollar, Chilean Peso, New Zealand Dollar and South African Rand can robustly predict commodity prices. Kilian (2009) explains the fluctuation in the oil price by using the global economic activity as a proxy of global demand. Joëts et al. (2017) find that U.S uncertainty can also affect commodity price uncertainty. Excess comovement in the commodity market as in Pindyck and Rotemberg (1990) is captured by the principal component of commodity prices for each commodity group. The quadratic terms of the principal component are also included to capture possible non-linearities of the data.

Following Jurado et al. (2015), the parametric stochastic process is defined as:

$$
\log \left[\left(u_{j, t+1}\right)^{2}\right]=a_{j}+b_{j} \log \left[\left(u_{j t}\right)^{2}\right]+k_{j} n_{j, t+1}
$$

where $e_{j, t+1}$ and $n_{j, t+1}$ are iid $N(0,1) r . v$. The stochastic volatility model allows for a shock to the second moment that is independent of the first moment, consistent with theoretical 
models of uncertainty. Using its definition, CPU is equal to the square root of the forecast error variance:

$$
\begin{aligned}
C P U_{j, t+1} & =\sqrt{E\left[\left(u_{j, t+1}\right)^{2} \mid I_{t}\right]} \\
& =\sqrt{\exp \left[a_{j}+b_{j} \log \left[\left(u_{j, t}\right)^{2}\right]+\frac{k_{j}^{2}}{2}\right]}
\end{aligned}
$$

where the stochastic volatility parameters $a_{j}, b_{j}, k_{j}$ are obtained from the least square residuals of the forecasting models using MCMC methods (Kastner, 2016).

Figure 1 plots the commodity uncertainty index for Australia that is constructed by weighting uncertainty in each commodity series by export shares. ${ }^{4}$ We observe three episodes of high uncertainty: (i) 2005; (ii) 2009; and (iii) 2015-2016. The first episode of high uncertainty in 2005 can be solely attributed to the high level of uncertainty in the iron ores market. ${ }^{5}$ The next two episodes of high uncertainty are common to other commodities that Australia exports. The second spike happened during the global financial crisis and the last spike could be associated with China's slow down in economic growth.

The lower panel of Figure 1 illustrates the role of including predictive information by comparing the CPU to an uncertainty estimate based on a potentially-mispecified simple model with no preditive information ('No Predictors'). ${ }^{6}$ It is worth noting that proper measurement of uncertainty requires removing the forecastable component before computing conditional volatility. Failure to do so will lead to estimates that treat forecastable components as uncertain components. We clearly observe the importance of accounting for additional information that has predictive power. The estimates of uncertainty are influenced by whether the predictable component is removed. The CPU index tends to be much lower compared to the case without

\footnotetext{
${ }^{4}$ The index only covers the list of the commodities that is reported in the Australian Department of Foreign Affairs and Trade (DFAT) Australia's goods and services by top 25 exports. The IMF commodity dataset, however, does not cover every commodity export that is covered by DFAT. The share of each exported commodity is re-weighted as a result. See the Appendix for further detail.

${ }^{5}$ See the Appendix for the plot of uncertainty for each major commodity that is exported by Australia.

${ }^{6}$ For the case of 'No Predictors', the forecasting regression (Equation (3)) becomes: $c p_{j, t+1}=u_{j, t+1} \epsilon_{j, t+1}$
} 
predictors ('No Predictors').

Figure 2 compares the CPU index with other established indices that are relevant to economic activity in Australia such as the Australian Economic Uncertainty index by Moore (2017), the Global Economic Policy Uncertainty index by Baker et al. (2016), CBOE volatility index (VIX) and the U.S. macroeconomic uncertainty index (Jurado et al. (2015)), and the Trade Policy Uncertainty index (TPU) (Caldara et al. (2020)). It is found that commodity uncertainty is distinct from other types of uncertainty. This can be seen by the low correlation between CPU and the domestic level of uncertainty in Australia by Moore (2017) where the correlation is 0.33; while that with the financial uncertainty (VIX) is 0.14 . CPU shares considerable correlation of 0.44 with the Jurado et al. (2015) index and of 0.42 with the Baker et al. (2016) global economic policy uncertainty. The correlation between the CPU and the TPU is also low, at the value of 0.14. In summary, this suggests that the CPU index is able to pick up uncertainty events that are highly relevant to the commodity market. The next section conducts a more formal comparison based on VAR evidence.

\section{VAR Evidence}

This section documents some empirical evidence on the impact of commodity price uncertainty shocks on the Australian economy by employing a medium-scale VAR:

$$
Z_{t}=\Phi(L) Z_{t-1}+\epsilon_{t}
$$

where $Z_{t}$ is the set of endogenous variables, $\Phi$ is a coefficient matrix, and $\epsilon_{t} \sim N(0, \Sigma)$ is a vector of reduced-form residuals. ${ }^{7}$

\footnotetext{
${ }^{7}$ The uncertainty index constructed in the earlier chapter has time varying volatility. However, the VAR model here features homoskedastic errors. Although the two-step approach employed in this paper is flexible, it may be somewhat contradictory. A recent paper by Carriero et al. (2018) improves the aforementioned inconsistency by proposing another approach by which uncertainty and its effect are estimated in a single step within the same model.
} 
The system consists of 11 variables: $C P_{t}, C P U_{t}, G D P_{t}, C_{t}, I_{t}, L_{t}, X_{t}, M_{t}, \pi_{t}, R_{t}, R E R_{t}$ starting from 1994Q3 to 2017Q2, where $C P_{t}$ is the commodity price index, $C P U_{t}$ is the commodity price uncertainty index, $G D P_{t}$ is real and seasonally adjusted gross domestic product, $C_{t}$ is consumption, $I_{t}$ is investment, $L_{t}$ is hours worked, $X_{t}$ is exports, $M_{t}$ is imports, $\pi_{t}$ is inflation, $R_{t}$ is the official cash rate, $R E R_{t}$ is real exchange rate. ${ }^{8}$ The VAR includes a constant and a linear time trend. Data sources are in the Appendix. The lag length, $L$, is determined by AIC. VARs are estimated via Bayesian methods with Minnesota priors. The identification of exogenous variations of uncertainty shocks is achieved by the Cholesky decomposition. The measure of uncertainty is placed second in the system of variables that isolates the effect of changes in commodity prices in a conservative way; while allowing uncertainty shocks to be exogenous to the rest of the economy, consistent with the small open economy assumption.

Figure 3 shows the VAR variable responses to a positive one-standard-deviation commodity uncertainty shock in the VAR with a $95 \%$ credible interval. All responses are in per cent, except for the cash rate and the inflation rate, which are in basis points. We see a significant and contractionary response of output, investment, and consumption; whilst, the response of hours worked is economically insignificant. The results show that GDP and consumption fall by approximately $0.15 \%$ at peak. The peak decrease in investment is approximately $0.75 \%$. The response of hours-worked, however, is found to be insignificant. Exports fall insignificantly whilst imports falls by $0.6 \%$. The inflation rate and the cash rate also fall by approximately 0.1 percentage points at peak. Last, since CPU is a second-moment shock that doesn't affect foreign demand for commodity, the negative wealth effect and precautionary response in the domestic economy effectively shift the supply curve to the left; thus causing an $0.5 \%$ appreciation in the real exchange rate. The response of the real exchange rate is also consistent with the change in exports. ${ }^{9}$

\footnotetext{
${ }^{8}$ Variables in logs are also multiplied by 100. A higher real exchange rate is interpreted as a deprecation to be consistent with the interpretation in the DSGE model.

${ }^{9}$ In the Appendix, the results are robust to a number of additional sensitivity checks including lag sensitivity;
} 
To illustrate the distinct effects of commodity price uncertainty shocks, Figure 4 compares the effects of different types of uncertainty shocks on output, consumption, investment and hours-worked. The effect of commodity uncertainty shocks on economic activity are larger than those of other uncertainties as captured by the Moore (2017) uncertainty index for Australia, the financial uncertainty index VIX, the Baker et al. (2016) global economic policy uncertainty index, the Jurado et al. (2015) uncertainty index for the U.S, and the trade policy uncertainty index constructed by Caldara et al. (2020). Whilst commodity uncertainty shocks are found to have a significant impact on output, consumption and investment; the effects of other uncertainty shocks on these macroeconomic indicators are found to be quite modest. Last, the effects of all these uncertainty shocks on hours-worked are insignificant. ${ }^{10}$

\section{Multi-Sector DSGE Model}

This section presents a business cycle model to provide a structural interpretation of the impact of commodity uncertainty shocks reported in Section 3. The DSGE model extends the multisector small open economy model in the spirit of Rees et al. (2016) to incorporate the effects of commodity price uncertainty shocks. The model is a natural environment for the purpose of this study because it structurally represents the Australian economy and it forms the basis for policy analysis in Australia.

the removal of commodity price; a different ordering of the variables in the VAR where uncertainty is placed last and the removal of the time trend.

${ }^{10}$ The full VAR responses can be found in the Appendix. Only the responses of real economic activity are presented to improve readability. In summary, the responses of net exports, the inflation rate, the cash rate and the real exchange rate to all uncertainty shocks are consistent with each other. 


\subsection{Household}

Households maximise their lifetime utility according to the following preferences which are separable in consumption, $C_{t}$, and hours worked, $L_{t}$.

$$
U=E_{0} \sum_{t=0}^{\infty} \beta^{t} \xi_{t}\left(\frac{\left(C_{t}-h C_{t-1}\right)^{1-\gamma}}{1-\gamma}-\frac{L_{t}^{1+\phi}}{1+\phi}\right)
$$

where $\beta$ is the intertemporal discount rate; $h$ is the parameter that controls habit persistence; $\gamma$ and $\phi$ are the inverse elasticities of intertemporal substitution and labour supply respectively. $\xi_{t}$ is a preference shock that follows an autoregressive process.

Households have access to incomplete international financial markets for domestic and foreign bonds. Households supply capital and labour to firms in the non-traded $(N)$, noncommodity tradable $(M)$ and commodity sector $(Z)$. Households own equity in domestic firms which provides them with profits. Households use their income from capital, labour and asset holdings to purchase bonds, consumption goods and investment goods.

The capital stock is sector-specific. The law of motion is given by:

$$
K_{j, t+1}=(1-\delta)\left(K_{j, t}\right)+\Upsilon_{t}\left[1-\frac{\Phi_{K}}{2}\left(\frac{I_{j, t}}{I_{j, t-1}}-1\right)^{2}\right] I_{j, t}
$$

for $j=N, M, Z$, where $\delta$ is the depreciation rate of capital which is common across sectors. The process of capital accumulation is subject to quadratic adjustment costs that are governed by the parameter $\Phi_{K}$. $\Upsilon_{t}$ is a shock to the marginal efficiency of investment and follows an autoregressive process.

Households enter each period with $B_{t-1}$ units of one-period risk-free bonds dominated in domestic currency and $B_{t-1}^{*}$ units of one-period risk-free bonds dominated in foreign currency. During the period, households receive wages and returns on capital. The household uses its income to buy new bonds and capital, and to purchase consumption goods. The variable $v_{t}$ is a risk premium terms that increases in the real quantity of outstanding foreign debt that is given 
by:

$$
v_{t}=\exp \left[-\Phi_{B}\left(\frac{S_{t} B_{t}^{*}}{P_{t} Y_{t}}\right)+\psi_{t}\right]
$$

where $\psi_{t}$ is a risk premium shock that follows an autoregressive process.

The household budget constraint is given by:

$$
\begin{aligned}
& P_{t} C_{t}+P_{t} I_{t}+B_{t}+S_{t} B_{t}^{*} \\
& \leq \sum_{j=n, m, z}\left(W_{j, t} L_{j, t}+R_{j, t} K_{j, t}\right)+B_{t-1} R_{t-1}+S_{t} B_{t-1}^{*} R_{t-1}^{*} v_{t-1}+\Gamma_{t}
\end{aligned}
$$

where $P_{t}$ is the price of the final goods in the economy; $S_{t}$ is the nominal exchange rate; $I_{t}=\sum_{j=N, M, Z} I_{j, t}$ is aggregate investment; $W_{j, t}$ and $R_{j, t}$ are the wage rate and rate of return on capital in sector $j ; \Gamma_{t}$ are aggregate profits from owning firms in the economy.

\subsection{The Commodity Sector}

There is a continuum of monopolistically-competitive commodity firms that sell differentiated products. In the domestic market, firms sell their output to a retailer, that transforms the intermediate products into homogeneous goods to sell to the final good sector. In the foreign market, firms sell their output to an exporter that transforms into homogeneous goods for sale in the overseas markets. The transformation of each firm's intermediate good follows the CES function: Expenditure minimisation yields the optimal demand for non-traded goods i:

$$
Y_{Z, t}^{k}=\left[\int_{0}^{1} Y_{Z, t}^{k}(i)^{\frac{\epsilon-1}{\epsilon}} d i\right]^{\frac{\epsilon}{\epsilon-1}}
$$

The demand functions for each firm's output in domestic, $k=D$; and foreign markets, $k=X$ are:

$$
Y_{Z, t}^{k}(i)=\left(\frac{P_{Z, t}(i)}{P_{Z, t}}\right)^{-\epsilon} Y_{Z, t}^{k}
$$

Each firm produces according to the following production function:

$$
Y_{Z, t}(i)=z_{Z, t}\left(K_{Z, t}(i)\right)^{\alpha_{Z}}\left(L_{Z, t}(i)\right)^{1-\alpha_{Z}}
$$

where $z_{Z, t}$ is the sector-specific technology shock that follows an autoregressive process; $K_{Z, t}$ and $L_{Z, t}$ are capital and labour used by firm $i ; \alpha_{Z}$ is the capital share in the commodity sector. 
In each period, a fraction $1-\theta_{Z}$ of firms is able to change price optimally by maximising their discounted profits subject to the demand function following Calvo (1983) pricing mechanism.

The presence of price rigidity departs from the traditional modeling approach in which the commodity sector is perfectly competitive with flexible prices (see, for example, Garcıa Cicco et al. (2013), Rees et al. (2016) or Kulish and Rees (2017)). Nominal rigidity in the commodity sector is in fact crucial to replicate the empirical finding in the previous section. It is motivated by Basu and Bundick (2017) who show that price rigidity is an important ingredient to replicate the macroeconomic comovement between output, investment, consumption and hours worked that we typically observe in the data. In a one-sector model, Basu and Bundick (2017) show that when price is flexible, higher uncertainty lowers consumption but causes an expansion in output, investment and hours-worked. The intuition is households work more to save more when uncertainty is higher. Since higher uncertainty doesn't affect capital stock today, it would cause output to be higher from higher labor input and ultimately, higher investment. On the other hand, under price stickiness, the direction of causality reverses. Higher uncertainty reduces demand for consumption good, resulting in lower output, investment and hours worked. Nevertheless, price stickiness in the commodity sector is in fact not an unusual modeling choice. A survey conducted by Cagliarini et al. (2011) shows ample evidence of price stickiness in the commodity sector in Australia.

While the domestic demand for commodities is determined by the domestic households and firms optimality conditions, foreign demand for commodities is given by following Justiniano and Preston (2010):

$$
Y_{Z, t}^{X}=\omega_{Z^{*}}\left(\frac{P_{Z, t}^{*}}{P_{t}^{*}}\right)^{-\eta_{Z}^{*}} Y_{t}^{*}
$$

In this setup, commodity firms are given an exogenous export price from the rest of the world that is different from their preset price in their domestic market such that $P_{Z, t} \neq S_{t} P_{Z, t}^{*}$. To accommodate time-varying uncertainty, it is assumed that the relative export price, $T_{Z, t}^{*}=\frac{P_{Z, t}^{*}}{P_{t}^{*}}$ 
follow an exogenous stochastic volatility process:

$$
\begin{aligned}
\log \left(\frac{T_{Z, t}^{*}}{T_{Z^{*}}}\right) & =\rho_{P_{Z}} \log \left(\frac{T_{Z, t-1}^{*}}{T_{Z^{*}}}\right)+\sigma_{P_{Z}, t} \epsilon_{P_{Z}, t} \\
\sigma_{P_{Z}, t} & =\left(1-\rho_{\sigma_{P_{Z}}}\right) \sigma_{P_{Z}}+\rho_{\sigma_{P_{Z}}} \sigma_{P_{Z}, t-1}+\kappa_{P_{Z}} \epsilon_{\sigma_{P_{Z}}}, t
\end{aligned}
$$

Time-varying volatility is incorporated in the form of stochastic volatility as $\sigma_{\rho_{Z}, t}$ is not constant. There are two independent innovations that affect the price component of commodity export demand, $T_{Z, t}^{*}$. The first innovation, $\epsilon_{P_{Z}, t}$ changes the level of the price by itself. In contrast, the second innovation, $\epsilon_{\sigma_{P_{Z}}, t}$ is the uncertainty innovation and determines the degree of volatility but not the level of price. The parameters $\sigma_{P_{Z}}$ and $\kappa_{P_{Z}}$ control the degree of mean volatility and stochastic volatility respectively.

\subsection{The Non-Commodity Tradable Sector}

The non-commodity tradable sector consists of a continuum of firms. Similar to the commodity sector, in the domestic market, firms sell their output to a retailer, that transforms the intermediate products into homogeneous goods to sell to the final good sector. In the foreign market, firms sell their output to an exporter that transforms into homogeneous goods for sale in overseas markets. The transformation of each firm's intermediate good follows the CES function:

$$
Y_{M, t}^{k}=\left[\int_{0}^{1} Y_{M, t}^{k}(i)^{\frac{\epsilon-1}{\epsilon}} d i\right]^{\frac{\epsilon}{\epsilon-1}}
$$

for $k=D, X$; where $D$ is goods that are sold domestically and $X$ denotes goods that are exported; $\epsilon$ is the substitution elasticity between different non-commodity tradable firms defined earlier. The demand functions for each firm's output in domestic, $k=D$; and foreign markets, $k=X$ are:

$$
Y_{M, t}^{k}(i)=\left(\frac{P_{M, t}(i)}{P_{M, t}}\right)^{-\epsilon} Y_{M, t}^{k}
$$


Each firm produces according to the following production function:

$$
Y_{M, t}(i)=z_{M, t}\left(K_{M, t}(i)\right)^{\alpha_{M}}\left(L_{M, t}(i)\right)^{1-\alpha_{M}}
$$

where $z_{M, t}$ is the sector-specific technology shock that follows an autoregressive process; $K_{M, t}$ and $L_{M, t}$ are capital and labor used by firm $i ; \alpha_{M}$ is the capital share in the non-commodity tradable sector. In each period, a fraction $1-\theta_{M}$ of firms is able to change price optimally by maximizing their discounted profits subject to the demand function according to the Calvo (1983) pricing mechanism.

Similar to the commodity sector, the demand curve for non-commodity export is given by:

$$
Y_{M, t}^{X}=\omega_{M^{*}}\left(\frac{P_{M, t}^{*}}{P_{t}^{*}}\right)^{-\eta_{M}^{*}} Y_{t}^{*}
$$

\subsection{The Non-Traded Sector}

There is a continuum of monopolistically competitive non-traded firms that sell differentiated products. Expenditure minimization yields the optimal demand for non-traded good i:

$$
Y_{N, t}(i)=\left(\frac{P_{N, t}(i)}{P_{N, t}}\right)^{-\epsilon} Y_{N, t}
$$

where $P_{N, t}=\left[\int_{0}^{1}\left(P_{N, t}(i)\right)^{1-\epsilon} d i\right]^{\frac{1}{1-\epsilon}}$ is the aggregate price index for non-tradable goods. These firms produce according to a Cobb-Douglas production function:

$$
Y_{N, t}(i)=z_{N, t}\left(K_{N, t}(i)\right)^{\alpha_{N}}\left(L_{N, t}(i)\right)^{1-\alpha_{N}}
$$

where $z_{N, t}$ is the sector-specific technology shock that follows an autoregressive process; $K_{N, t}$ and $L_{N, t}$ are the quantities of capital and labor used by firm $i ; \alpha_{N}$ is capital share in the production function. Firms face staggered price setting following the Calvo (1983) pricing mechanism. In each period, only a fraction $1-\theta_{N}$ of firms can change prices. 


\subsection{The Import Sector}

The output of the import sector is an aggregate constructed from a continuum of imported varieties, which importers import at price $S_{t} P_{t}^{*}$, where $S_{t}$ is the nominal exchange rate and $P_{t}^{*}$ is the price in foreign currency. Importing firms then sell them in the domestic market at price $P_{F, t}(i)$. The demand function for each variety $i$ is:

$$
Y_{F, t}(i)=\left(\frac{P_{F, t}(i)}{P_{F, t}}\right)^{-\epsilon} Y_{F, t}
$$

Importing firms also face staggered price setting as in Calvo (1983), where only a fraction $1-\theta_{F}$ is able to change prices. The wedge between the world market price of foreign goods paid by importing firms $\left(S_{t} P_{t}^{*}\right)$ and the domestic currency price $\left(P_{F, t}\right)$ of these goods paid by the domestic consumers is the law-of-one-price gap or is also called the real marginal cost of importing firm:

$$
M C_{F, t}=\frac{S_{t} P_{t}^{*}}{P_{F, t}}
$$

\subsection{The Final Goods Sector}

A competitive firm produces final goods by combining composite non-tradable goods, $Y_{N, t}$ and composite tradable goods, $Y_{T, t}$ according to the technology:

$$
F G_{t}=\left[\left(1-\omega_{N}\right)^{\frac{1}{\eta}} Y_{T, t}^{\frac{\eta-1}{\eta}}+\omega_{N}^{\frac{1}{\eta}} Y_{N, t}^{\frac{\eta-1}{\eta}}\right]^{\frac{\eta}{1-\eta}}
$$

where $\omega_{N}$ is the share of non-traded goods in the final domestic goods; and $\eta$ is the elasticity of substitution between non-tradable and tradable goods.

The composite of domestically-produced commodities and non-commodity goods, $Y_{Z, t}^{D}$ and $Y_{M, t}^{D}$; and imported tradable goods, $Y_{F, t}$ are produced according to the technology; with substitution elasticity, $\nu$; and $\omega_{F}$ is the share of import goods in the tradable goods bundles:

$$
\left.Y_{T, t}=\left[\left(1-\omega_{F}-\omega_{Z}\right)^{\frac{1}{\nu}} Y_{M, t}^{D} \frac{\nu-1}{\nu}+\omega_{F}^{\frac{1}{\nu}} Y_{F, t}^{\frac{\nu-1}{\nu}}+\omega_{Z}^{\frac{1}{\nu}} Y_{Z, t}^{D}\right]^{\frac{\nu-1}{\nu}}\right]^{\frac{\nu}{\nu-1}}
$$


A representative firm's profit maximization yields the following demand functions:

$$
\begin{gathered}
Y_{M, t}^{D}=\left(1-\omega_{F}-\omega_{Z}\right)\left(\frac{P_{M, t}}{P_{T, t}}\right)^{-\nu} Y_{T, t} \\
Y_{Z, t}^{D}=\omega_{Z}\left(\frac{P_{Z, t}}{P_{T, t}}\right)^{-\nu} Y_{T, t} \\
Y_{F, t}=\omega_{F}\left(\frac{P_{F, t}}{P_{T, t}}\right)^{-\nu} Y_{T, t}
\end{gathered}
$$

The non-traded, domestically-produced traded, $Y_{M, t}$ and imported goods, $Y_{F, t}$ are all bundles of a continuum of imperfectly substitutes, and $\epsilon$ is the substitution elasticity between firm $i$, for $j=N, M, F$

$$
Y_{j, t}=\left(\int_{0}^{1} Y_{j, t}(i)^{\frac{\epsilon-1}{\epsilon}} d i\right)^{\frac{\epsilon}{\epsilon-1}}
$$

Profit maximisation by the final goods producer implies that the final goods price index is:

$$
P_{t}=\left[\left(1-\omega_{N}\right) P_{T, t}^{1-\eta}+\omega_{N} P_{N, t}^{1-\eta}\right]^{\frac{1}{1-\eta}}
$$

and the price index of the tradable goods is:

$$
P_{T, t}=\left[\left(1-\omega_{F}-\omega_{Z}\right) P_{M, t}^{1-\nu}+\omega_{F} P_{F, t}^{1-\nu}+\omega_{Z} P_{Z, t}^{1-\nu}\right]^{\frac{1}{1-\nu}}
$$

\subsection{Monetary Policy}

The domestic central bank follows a Taylor rule that responds to inflation, output growth and the real exchange rate:

$$
\begin{aligned}
& \log \left(\frac{R_{t}}{R}\right)=\rho_{R} \log \left(\frac{R_{t-1}}{R}\right) \\
& +\left(1-\rho_{R}\right)\left[\phi_{\pi} \log \left(\frac{\Pi_{t}}{\Pi}\right)+\phi_{Y} \log \left(\frac{Y_{t}}{Y_{t-1}}\right)+\phi_{Q} \log \left(\frac{Q_{t}}{Q}\right)\right]+\epsilon_{R, t}
\end{aligned}
$$

The parameter $\rho_{R}$ defines the degree of interest rate smoothing. While the response to inflation, output growth and real interest rate deviations from target are given by $\phi_{\pi}, \phi_{Y}$ and $\phi_{Q}$ respectively. 


\subsection{Market Clearing}

The goods market clearing condition requires that:

$$
\begin{gathered}
D F D_{t}=C_{t}+I_{t} \\
Y_{i, t}=Y_{i, t}^{D}+Y_{i, t}^{X} \quad \text { for } \quad i=M, Z \\
Y_{i, t}=\frac{z_{i, t} K_{i, t}^{\alpha_{i}} L_{i, t}^{1-\alpha_{i}}}{\Theta_{i, t}} \text { for } i=M, N, Z
\end{gathered}
$$

Equation 34 is the market clearing condition for the domestic final goods. Equation 35 states that all commodity and non-commodity tradable goods must be sold at home or abroad. Equation 36 represents market clearing conditions in the commodity sector, the non-commodity tradable sector and non-traded sector respectively. $\Theta_{j, t}$, for $j=Z, N, M$ measures the price dispersion by staggered price setting. By the properties under Calvo pricing:

$$
\Theta_{j, t}=\theta_{j}\left(\frac{\Pi_{j, t-1}^{\chi}}{\Pi_{i, t}}\right)^{-\epsilon} \Theta_{j, t-1}+\left(1-\theta_{j}\right) \bar{\Pi}_{j, t}^{-\epsilon}
$$

Nominal GDP is given by:

$$
N G D P_{t}=P_{N, t} Y_{N, t}+P_{M, t} Y_{M, t}+P_{Z, t} Y_{Z, t}
$$

Real GDP is:

$$
Y_{t}=\frac{P_{N, t}}{P_{t}} Y_{N, t}+\frac{P_{M, t}}{P_{t}} Y_{M, t}+\frac{P_{Z, t}}{P_{t}} Y_{Z, t}
$$

The hours-worked index includes hours allocated to the non-traded, non-resource tradable and resource sectors,

$$
L_{t}=\left[L_{N, t}^{1+\phi_{s}}+L_{M, t}^{1+\phi_{s}}+L_{Z, t}^{1+\phi_{s}}\right]^{\frac{1}{1+\phi_{s}}}
$$

where $\phi_{s} \geq 0$ is the parameter that governs labour mobility across sectors in response to wage differentials. 
The supply of investment goods is equal to the demand for investment goods across sectors:

$$
I_{t}=I_{N, t}+I_{M, t}+I_{Z, t}
$$

In the steady state, price level is not stationary but relative prices are. It is therefore useful to define the following relative prices:

$$
T_{N, t}=\frac{P_{N, t}}{P_{t}} ; T_{M, t}=\frac{P_{M, t}}{P_{t}} ; T_{Z, t}=\frac{P_{Z, t}}{P_{t}} ; T_{Z, t}^{*}=\frac{P_{Z, t}^{*}}{P_{t}^{*}} ; T_{T, t}=\frac{P_{T, t}}{P_{t}} ; T_{F, t}=\frac{P_{F, t}}{P_{t}} ; Q_{t}=\frac{S_{T} P_{t}^{*}}{P_{t}}
$$

Aggregate inflation is linked to the tradable inflation and non-tradable inflation according to:

$$
\Pi_{t}=\left[\left(1-\omega_{N}\right)\left(\Pi_{T, t} T_{T, t-1}\right)^{1-\eta}+\omega_{N}\left(\Pi_{N, t} T_{N, t-1}\right)^{1-\eta}\right]^{\frac{1}{1-\eta}}
$$

Tradable inflation is linked to non-commodity tradable inflation and import inflation according to:

$$
\Pi_{T, t}=\left[\left(1-\omega_{F}-\omega_{Z}\right)\left(\frac{\Pi_{M, t} T_{M, t-1}}{T_{T, t-1}}\right)^{1-\nu}+\omega_{Z}\left(\frac{\Pi_{Z, t} T_{Z, t-1}}{T_{T, t-1}}\right)^{1-\nu}+\omega_{F}\left(\frac{\Pi_{F, t} T_{F, t-1}}{T_{T, t-1}}\right)^{1-\nu}\right]^{\frac{1}{1-\nu}}
$$

\subsection{Foreign Economy and the Current Account}

Following Justiniano and Preston (2010) and Kulish and Rees (2017), foreign demand for domestic non-commodity goods is given by:

$$
Y_{M, t}^{X}=\omega_{M^{*}}\left(\frac{P_{H, t}}{S_{t} P_{t}^{*}}\right)^{-\eta *} Y_{t}^{*}
$$

Net exports in nominal terms are determined by export values from the commodity sector and the non-commodity tradable sector less import values.

$$
N X_{t}=P_{M, t} Y_{M, t}^{X}+S_{t} P_{Z, t}^{*} Y_{Z, t}^{X}-S_{t} P_{t}^{*} Y_{F, t}
$$

The current account governs the economy's net foreign assets over time is given by:

$$
\frac{S_{t} B_{t}^{*}}{R_{t}^{*} v_{t}}=S_{t} B_{t-1}^{*}+N X_{t}
$$




\section{Results and Discussion}

\subsection{Model Solution}

The model is solved by using a third order perturbation method because shocks to volatility only appear and have a direct effect in the third-order terms as discussed by Fernández-Villaverde et al. (2011). The responses of the economy to uncertainty shocks are those starting from the risk-adjusted steady state and assuming that all other shocks are equal to zero, which capture and isolate the economic effects of uncertainty shocks from other shocks. Moreover, since this is a large model, several parameters are fixed to conventional values to ensure that the first moment of the model is consistent with the long-run property of the data. Several key structural parameters are estimated by minimizing the distance between impulse responses generated from simulations of the DSGE model and those from VAR model to provide a connection. Below is the discussion of the selection of parameters.

Calibration: The list of calibrated parameters is presented in Table 1. The model is calibrated to zero inflation state where both domestic inflation and foreign inflation, $\Pi=\Pi^{*}=$ 1 in the steady state. The household discount rate, $\beta$, is 0.989 . Together, this implies an annualized steady state nominal interest rate of $4.5 \%$.

The capital shares in each sector, $\alpha_{Z}, \alpha_{N}, \alpha_{M}$ are set according to the average values in national accounts data. The mark-up parameters in all sectors, $\epsilon$, is set equal to 11 to give a mark up of $10 \%$. The intersectoral elasticity of final demand, $\eta$, is set to 0.8 which is consistent with the broad literature, for instance, Justiniano and Preston (2010), Kulish and Rees (2017), or Rees et al. (2016). The willingness of workers to move between sectors, $\phi_{s}$, is set to 1 . Risk aversion, $\gamma$, is set to 1 . The monetary policy rule is set accordingly to the values in Rees et al. (2016). The interest rate smoothing Taylor rule coefficient, $\rho_{R}$, is 0.86 . The feedback coefficient to inflation, $\phi_{\pi}$ is 1.42 ; the feedback coefficient to the output gap, $\phi_{Y}$ is 0.05 ; and the feedback coefficient to the real exchange rate deviation, $\phi_{Q}$ is approximately 0 which corroborates earlier 
findings that monetary policy in Australia does not respond directly to exchange rate movements. The inverse of the Frisch labor supply elasticity, $\phi$; the habit persistence parameter, $h$; the capital adjustment cost parameter, $\Phi_{K}$; and the Calvo pricing parameters across all sectors are however estimated. The parameters governing the exogenous processes are taken from Rees et al. (2016) except those governing foreign economy processes are taken from Kulish and Rees (2017) because of the non-standard processes in the former. Those capture commodity price and commodity price uncertainty processes are estimated (see Equation 15 and 16).

Other parameters are calibrated to match the long-run properties of the data. These include the depreciation rate, $\delta$; the share of non-traded goods, commodity goods and foreign goods, $\omega_{N}, \omega_{Z}$ and $\omega_{Z}$, respectively; the overseas elasticity of substitution for commodity goods and non-commodity goods, $\eta_{Z^{*}}, \eta_{M^{*}}$; the elasticity of substitution between foreign goods and domestic goods, $\nu$; the steady state foreign demand for commodity, $Y_{Z}^{*}$, the constant in the commodity and non-commodity export function, $\omega_{Z^{*}}$ and $\omega_{M^{*}}$, respectively; and the steady-state foreign asset level, $b^{*}$.

Table 2 shows the long-run properties of the model versus the averages in the data. The model is able to capture many important features of the data.

Estimation: The set of estimated structural parameters includes the habit persistence parameter, $h$; the inverse of the Frisch labor supply elasticity, $\phi$; the capital adjustment cost parameter, $\Phi_{K}$; the Calvo pricing parameters in all sectors, $\theta_{M}, \theta_{M}, \theta_{N}, \theta_{Z}$; the persistence of commodity price, $\rho_{P_{Z}}$ and commodity price uncertainty, $\rho_{\sigma_{Z}}$; the mean of volatility parameter, $\sigma_{Z}$; and the mean of stochastic volatility, $\kappa$. Following Christiano et al. (2005), this set of parameters is estimated so that it minimizes the DSGE model responses to the VAR model responses. Formally, the estimator is written as:

$$
V=\underset{\Omega}{\arg \min }\left[\hat{I R F_{h}}-I R F_{h}(\Omega)\right]^{\prime} W^{-1}\left[I \hat{R} F_{h}-I R F_{h}(\Omega)\right]
$$

where $\Omega \triangleq\left(h, \theta, \Phi_{K}, \theta_{M}, \theta_{N}, \theta_{F}, \theta_{Z}, \rho_{\sigma_{Z}}, \sigma_{Z}, \kappa\right)$ is the vector of estimated parameters; $I \hat{R} F$ is the 
VAR impulse responses of the real economic activity variables including output, consumption, investment, hours worked, exports and imports to uncertainty shocks; ${ }^{11} \operatorname{IRF}(\Omega)$ is the DSGE model-implied impulse responses; $\mathrm{h}$ is IRF horizons; $W$ is the diagonal matrix with equal weight. $^{12}$

The estimated parameters are presented in Table 3 with the standard errors reported in parentheses. The majority of the estimated parameters are within the reported range in the literature. The habit persistence parameter, $h$ is estimated to be 0.93 to capture the large degree of inertia in consumption response to uncertainty shocks, and is higher to the estimated value of 0.77 in Rees et al. (2016). The parameter governing capital adjustment cost is 3.09, which is larger than the value in Rees et al. (2016) but is higher than the estimated value in an earlier Australian study by Jääskelä and Nimark (2011). The Calvo pricing parameters for the all sectors are also consistent with the range of the reported values in Cagliarini et al. (2011) and Rees et al. (2016). In particular, the estimation shows that the presence of price rigidity in the commodity sector is a crucial ingredient to match the empirical evidence. The estimated Calvo parameter is 0.58, and is smaller than the survey-value of 0.75 in Cagliarini et al. (2011).

The inverse of Frisch labor supply elasticity, $\phi$ is estimated to be significantly large at the value of 16.99. This is significantly larger than from the standard value of 2 in the literature (see, for example, Rees et al. (2016) or Kulish and Rees (2017)). The large parameter value is necessary to reflect the insignificant and inelastic response of hours worked that we observe from the VAR.

\footnotetext{
${ }^{11}$ Preliminary experiments show that the DSGE impulse responses of nominal interest rate or inflation rate to an uncertainty shock fail to replicate those of VAR in terms of magnitude. As a result, the estimation chooses to focus only on minimizing the responses of the real economic activity variables.

${ }^{12}$ The equally-weighted diagonal matrix, $W$, is employed because the diagonal matrix with the variances of the VAR impulse responses along the main diagonal gives too much weight to the near-term IRFs in the matching procedure (due to much narrower credible intervals) and therefore does not provide a desirable match for the entire horizons.
} 
To match the empirical responses, the persistence of the commodity price shock process is estimated to be 0.62 and is lower than the persistence parameter of 0.77 observed in the empirical IRFs, or existing estimates that range from 0.81 to 0.94 (for example, Gómez-González et al. (2013); Hansen and Gross (2018) or Rees et al. (2016)). ${ }^{13}$ The persistence of uncertainty shock is, however, larger than what is observed in the empirical model. While the uncertainty shock in the empirical model dissipates after 4 periods, the uncertainty shock in the DSGE has to be more persistent. The mean volatility parameter, $\sigma_{Z}$, and stochastic volatility parameter, $\kappa$, together imply that a 1 standard deviation uncertainty shock causes uncertainty to go up by around $27 \%$, greater than a $17 \%$ increase in the data.

\subsection{The Economic Effects of Commodity Price Uncertainty}

The DSGE model responses are shown to match the responses of the real economic activity variables to an identified uncertainty shock in the data as shown in Figure 3. Figure 5 and 6 present the baseline results for the aggregate variables and the sectoral variables respectively. These figures also include a battery of sensitivity checks with respect to key parameters that might affect the transmission mechanism including the role of nominal rigidities in the commodity sector, labor supply elasticities, the size of uncertainty shocks, the persistence of uncertainty shocks, and a modified monetary policy rule.

The uncertainty shock by construction is a second-moment shock such that commodity prices (Figure 5) and foreign demand for commodity output (Figure 6) are unaffected. In addition to the precautionary saving motive through reducing households consumption, it is found that the endogeneous increases in markups channel as discussed in Fernández-Villaverde et al. (2015) is central to the transmission of commodity price uncertainty shock that reduces output, consumption and investment. Interestingly, while the literature typically documents

\footnotetext{
${ }^{13}$ The VAR evidence shows that in period of 4 quarters, commodity price falls gradually to around $35 \%$ of its peak after its own shock. This observation suggests that if the commodity price shock is approximated by an $\mathrm{AR}(1)$ process as in the DSGE model, then the persistence parameter should be about $0.77\left(0.77^{4} \sim 0.35\right)$.
} 
that an uncertainty shock is associated with a fall in hours worked, the model also shows that hours worked do not fall and is consistent with the empirical evidence. The DSGE model is able to account for that by making labor supply inelastic through assigning a large value of the inverse of Frisch labor supply elasticity. The DSGE model with elastic labor supply with the inverse of Frisch labor supply elasticity set to the standard value of 2 shows a much larger drop in hours worked (see Figure 5).

The results show that nominal rigidities and markups are central to the transmission of commodity price uncertainty shocks. The significant economic effects of commodity price uncertainty shocks no long exist under flexible prices. Whilst commodity price uncertainty shocks neither affect commodity price nor foreign demand for commodity export by construction; higher uncertainty about commodity price leads to higher variance of future desired prices. When adjusting prices is costly, wholesale firms in the commodity sector respond to higher commodity price uncertainty by increasing markups in order to avoid selling at a relatively low price in the future (see Marginal Cost Z - Figure 6). This precautionary increase in markup is a result of the fact that wholesale firm's losses from pricing below the period by period profit maximizing level are larger than the losses from overpricing. As a result, immediately after an uncertainty shock, output falls the largest in the commodity sector where the peak decline is approximately $2 \%$. Such a large fall creates a negative wealth effect for the rest of the economy that is followed by the fall in investment and consumption. There is some sectoral allocation effects to the other sectors, notably seen by a small increase in production in the non-commodity tradable sector (see Output M in Figure 6). Output in the non-traded sector (see Output N in Figure 6) falls significantly less, reflecting a marginally larger impact of the negative wealth effect.

Next, the external sector responses in the DSGE model are consistent with the VAR evidence. Exports fall initially by small amount, mostly driven by an increase in markups in the non-commodity tradeable sector (See Marginal Cost M - Figure 6) and recover subsequently. The behavior exports in general and are in line with the response of the real exchange rate. It 
should also be noted that although not explicitly targeted, the response of the real exchange rate in the DSGE model is also consistent with that of the VAR. Imports show persistent decline, consistent with the negative wealth effect.

Furthermore, although both inflation and the cash rate fall in the DSGE model, the magnitude is not as large as what is documented in the VAR evidence. This is because whilst uncertainty depresses domestic demand that lowers prices, higher mark-ups create an opposite force that result in a minimal change in inflation. It is however shown that by modifying the Taylor rule that allows the central bank to react to higher uncertainty, CPU shocks can generate a relatively larger response of inflation and the interest rate, yet still small on the economy. The intuition is that higher nominal interest rate creates an additional recessionary effect on the economy. It further dampens aggregate demand and marginal cost. The lower marginal cost then leads to a fall in inflation. ${ }^{14}$

Taken together, higher commodity uncertainty creates a negative wealth effect in the country as seen by the fall in aggregate output and investment by approximately $0.15 \%$ and $0.7 \%$ at peak respectively. We also observe a precautionary saving effect as aggregate consumption falls by more than $0.1 \%$ at peak. Hours-worked, on the other hand, is inelastic.

\footnotetext{
${ }^{14}$ An alternative Taylor rule that allows the central bank to react to higher uncertainty can produce a deflationary effect of uncertainty shocks on the economy, although small. This problem is also encountered in Fernández-Villaverde et al. (2015). Following their approach, the monetary policy rule is rewritten as:

$$
\begin{aligned}
& \log \left(\frac{R_{t}}{R}\right)=\rho_{R} \log \left(\frac{R_{t-1}}{R}\right) \\
& +\left(1-\rho_{R}\right)\left[\phi_{\pi} \log \left(\frac{\Pi_{t}}{\Pi}\right)+\phi_{Y} \log \left(\frac{Y_{t}}{Y_{t-1}}\right)+\phi_{Q} \log \left(\frac{Q_{t}}{Q}\right)+\phi_{U} \log \left(\frac{\sigma_{Z, t}}{\sigma_{Z}}\right)\right]
\end{aligned}
$$

where $\phi_{U}$ is the monetary policy coefficient with respect to higher uncertainty. $\phi_{U}$ is then set to be 0.01 . The choice of this parameter ensures that the responses of other real economic variables do not change significantly from the baseline model but it is enough to cause inflation to fall after an uncertainty shock.
} 


\subsection{Model-Based Support for Empirical Identification}

A timing restriction is imposed in the VAR analysis to identify CPU shocks. This ordering assumes that CPU shocks in the VAR model can have an immediate impact on other macroeconomic variables in the system, but other shocks do not affect uncertainty on impact. This section provides an assessment on whether such an empirical identification is supported by the DSGE model through employing a simulation exercise.

The simulation exercise suggests that the recursive identification strategy can recover the true macroeconomic effects of CPU shocks. This is done by simulating the data from the DSGE model for a sample of 100 years (400 observations), which is considered a long and plausible length for economic analysis. ${ }^{15}$ The simulated data is then estimated under the same structural VAR framework in Section 3. Figure 7 compares the model responses to the responses in an identified VAR with recursive assumption that uses simulated data. Overall, the figure shows that the VAR empirical strategy is supported by the theoretical model which is illustrated by the fact that the empirical strategy is able to replicate the true model responses closely.

\section{Conclusion}

Increasing uncertainty about commodity price is an important issue for a small open economy that relies on commodity exports. This paper investigates the possible effects of commodity uncertainty shocks on economic activity and discusses the underlying transmission mechanisms by using Australia as a case study. First, it proposes a novel measure of commodity price uncertainty that is typically faced by Australian commodity exporters. It shows that Australia has

\footnotetext{
${ }^{15} 5000$ observations are actually simulated. The first 1000 observations are dropped to eliminate any initial condition effects. The next 400 observations are kept and estimated; then contrasted to the estimation of 4000 observations to check whether there is any estimation gains that can be attained as the sample size becomes significantly larger. Nevertheless, the Appendix shows that the results are affected by the initial condition effects but not by the sample size.
} 
experienced several episodes of heightened commodity uncertainty in the past and uncertainty has become much more volatile recently. The empirical evidence shows the significant effect of commodity price uncertainty shocks on real economic activity. The transmission of commodity price uncertainty is then studied through the lens of a non-linear DSGE model with multiple production sectors. It is found that the effects of commodity price uncertainty shocks in the theoretical model are in line with the empirical evidence. The DSGE framework emphasizes the role of nominal rigidity as a key ingredient in the transmission of commodity price uncertainty shocks.

\section{Acknowledgment}

The author would like to thank Andrea Carriero, Efrem Castelnuovo, Jamie Cross, Yunjong Eo, Pablo Guerron-Quintana, James Hansen, Mariano Kulish, James Morley, Adrian Pagan, Giovanni Pellegrino, Bruce Preston, Kalvinder Shields, Tim Robinson, Jiao Wang, Benjamin Wong and participants at the University of Melbourne Seminar, the 2019 Australian Conference of Economists in Canberra, the 2019 International Association of Applied Econometrics (IAAE) Conference in Cyprus, the 2019 Australasian Macroeconomics Society Workshop (WAMS) in Hobart for helpful feedback that greatly improves this manuscript. The author would also gratefully acknowledge financial support by the Australian Research Council via the Discovery Grant DP160102281 and the University of Melbourne Faculty Grant \& Research Scholarship.

\section{References}

Baker, S. R., Bloom, N., and Davis, S. J. (2016). Measuring economic policy uncertainty. The Quarterly Journal of Economics, 131(4):1593-1636.

Başkaya, Y. S., Hülagü, T., and Küçük, H. (2013). Oil price uncertainty in a small open economy. IMF Economic Review, 61(1):168-198. 
Basu, S. and Bundick, B. (2017). Uncertainty shocks in a model of effective demand. Econometrica, 85(3):937-958.

Bloom, N. (2014). Fluctuations in uncertainty. Journal of Economic Perspectives, 28(2):153176.

Born, B. and Pfeifer, J. (2014). Risk matters: The real effects of volatility shocks: Comment. American Economic Review, 104(12):4231-4239.

Cagliarini, A., Robinson, T., and Tran, A. (2011). Reconciling microeconomic and macroeconomic estimates of price stickiness. Journal of Macroeconomics, 33(1):102-120.

Caldara, D., Iacoviello, M., Molligo, P., Prestipino, A., and Raffo, A. (2020). The economic effects of trade policy uncertainty. Journal of Monetary Economics, 109:38 - 59 .

Calvo, G. A. (1983). Staggered prices in a utility-maximizing framework. Journal of Monetary Economics, 12(3):383-398.

Carriero, A., Clark, T. E., and Marcellino, M. (2018). Measuring uncertainty and its impact on the economy. Review of Economics and Statistics, forthcoming.

Castelnuovo, E. (2019). Domestic and global uncertainty: A survey and some new results. Technical report, mimeo.

Castelnuovo, E., Lim, G., and Pellegrino, G. (2017). A short review of the recent literature on uncertainty. Australian Economic Review, 50(1):68-78.

Chen, Y.-C., Rogoff, K. S., and Rossi, B. (2010). Can exchange rates forecast commodity prices? The Quarterly Journal of Economics, 125(3):1145-1194.

Christiano, L., Eichenbaum, M., and Evans, C. (2005). Nominal rigidities and the dynamic effects of a shock to monetary policy. Journal of Political Economy, 113(1):1-45. 
Cross, J., Nguyen, B., and Tran, T. D. (2019). The role of precautionary and speculative demand in the global market for crude oil.

Crowley, M., Meng, N., and Song, H. (2018). Tariff scares: Trade policy uncertainty and foreign market entry by chinese firms. Journal of International Economics, 114:96 - 115 .

Davis, S. J. (2016). An index of global economic policy uncertainty. NBER Working Paper No. 22740.

Dehn, J. (2000). Commodity price uncertainty in developing countries. The World Bank.

Dungey, M. and Pagan, A. (2000). A structural VAR model of the Australian economy. Economic record, 76(235):321-342.

Elder, J. and Serletis, A. (2010). Oil price uncertainty. Journal of Money, Credit and Banking, 42(6):1137-1159.

Fernández-Villaverde, J., Guerrón-Quintana, P., Kuester, K., and Rubio-Ramírez, J. (2015). Fiscal volatility shocks and economic activity. American Economic Review, 105(11):3352-84.

Fernández-Villaverde, J., Guerrón-Quintana, P., Rubio-Ramírez, J. F., and Uribe, M. (2011). Risk matters: The real effects of volatility shocks. American Economic Review, 101(6):253061.

Fernández-Villaverde, J. and Guerrón-Quintana, P. A. (2020). Uncertainty shocks and business cycle research. Review of Economic Dynamics, 37:S118 - S146. The twenty-fifth anniversary of "Frontiers of Business Cycle Research".

Garcıa Cicco, J., Heresi, R., and Naudon, A. (2013). The real effects of global risk shocks in small open economies. Technical report, mimeo.

Gómez-González, P., Rees, D., et al. (2013). Stochastic Terms of Trade Volatility in Small Open Economies. Economic Research Department, Reserve Bank of Australia. 
Handley, K. (2014). Exporting under trade policy uncertainty: Theory and evidence. Journal of International Economics, 94(1):50-66.

Handley, K. and Limão, N. (2015). Trade and investment under policy uncertainty: Theory and firm evidence. American Economic Journal: Economic Policy, 7(4):189-222.

Handley, K. and Limão, N. (2017). Policy uncertainty, trade, and welfare: Theory and evidence for china and the united states. American Economic Review, 107(9):2731-83.

Hansen, J. and Gross, I. (2018). Commodity price volatility with endogenous natural resources. European Economic Review, 101:157-180.

Jääskelä, J. P. and Nimark, K. (2011). A medium-scale new keynesian open economy model of australia. Economic Record, 87(276):11-36.

Jääskelä, J. P. and Smith, P. (2013). Terms of trade shocks: What are they and what do they do? Economic Record, 89(285):145-159.

Jo, S. (2014). The effects of oil price uncertainty on global real economic activity. Journal of Money, Credit and Banking, 46(6):1113-1135.

Joëts, M., Mignon, V., and Razafindrabe, T. (2017). Does the volatility of commodity prices reflect macroeconomic uncertainty? Energy Economics, 68:313-326.

Jurado, K., Ludvigson, S. C., and Ng, S. (2015). Measuring uncertainty. American Economic Review, 105(3):1177-1216.

Justiniano, A. and Preston, B. (2010). Monetary policy and uncertainty in an empirical small open-economy model. Journal of Applied Econometrics, 25(1):93-128.

Kastner, G. (2016). Dealing with stochastic volatility in time series using the r package stochvol. Journal of Statistical Software, Articles, 69(5):1-30. 
Kilian, L. (2009). Not all oil price shocks are alike: Disentangling demand and supply shocks in the crude oil market. American Economic Review, 99(3):1053-69.

Kulish, M. and Rees, D. M. (2017). Unprecedented changes in the terms of trade. Journal of International Economics, 108:351-367.

Moore, A. (2017). Measuring economic uncertainty and its effects. Economic Record, June:1-26.

Nguyen, B., Okimoto, T., and Tran, T. D. (2019). Uncertainty and sign-dependent effects of oil market shocks.

Pfeifer, J., Born, B., and Müller, G. (2012). Terms of trade uncertainty and business cycle fluctuations.

Pindyck, R. S. and Rotemberg, J. J. (1990). The excess co-movement of commodity prices. The Economic Journal, 100(403):1173-1189.

Rees, D. M., Smith, P., and Hall, J. (2016). A multi-sector model of the Australian economy. Economic Record, 92(298):374-408.

Steinberg, J. B. (2019). Brexit and the macroeconomic impact of trade policy uncertainty. Journal of International Economics, 117:175 - 195. 
Table 1: Calibrated Parameters

\begin{tabular}{|c|c|c|}
\hline Parameter & Value & Description \\
\hline \multicolumn{3}{|c|}{ Technology and Policy } \\
\hline$R$ & 1.011 & steady state nominal interest rate \\
\hline$R^{*}$ & 1.011 & steady state nominal foreign interest rate \\
\hline$\Pi$ & 1 & steady state inflation rate \\
\hline$\Pi^{*}$ & 1 & steady state foreign inflation rate \\
\hline$\delta$ & 0.009 & depreciation rate \\
\hline$\Phi_{K}$ & 1 & capital adjustment cost \\
\hline$\frac{B^{*}}{P^{*}}$ & 0.09 & steady state foreign debt \\
\hline$\rho_{R}$ & 0.8 & interest smoothing coefficient \\
\hline$\phi_{\Pi}$ & 1.5 & feedback coefficient to inflation \\
\hline$\phi_{Y}$ & 0.35 & feedback coefficient to output growth \\
\hline$\phi_{Q}$ & 0 & feedback coefficient to real exchange rate \\
\hline \multicolumn{3}{|c|}{ Household } \\
\hline$\beta$ & 0.989 & discount factor \\
\hline$\phi_{s}$ & 1 & intersectorla elasticity labour supply \\
\hline$\gamma$ & 1 & risk aversion \\
\hline$\nu$ & 0.52 & intersectoral elasticity of subsitution in tradable goods bundle \\
\hline$\epsilon$ & 11 & Markups in all sectors \\
\hline$\eta$ & 0.8 & intersectoral elasticity of subsitution in exports \\
\hline$\eta_{Z}^{*}$ & 1.1 & elasticty between and domestic and foreign goods (sector Z) \\
\hline$\eta^{*}$ & 1.1 & elasticty between and domestic and foreign goods (sector M) \\
\hline \multicolumn{3}{|c|}{ Non-traded Sector $(\mathrm{N})$} \\
\hline$\alpha_{N}$ & 0.3 & share of capital \\
\hline$\omega_{N}$ & 0.617 & weights of $\mathrm{N}$ goods in domestic demand \\
\hline \multicolumn{3}{|c|}{ Commodity Sector (Z) } \\
\hline$\alpha_{Z}$ & 0.7 & share of capital \\
\hline$\omega_{Z}$ & 0.14 & weights of $\mathrm{Z}$ goods in tradable goods bundle \\
\hline$\omega_{Z *}$ & 1.6 & governs share of $\mathrm{Z}$ goods \\
\hline$y_{Z}^{*}$ & 0.83 & governs share of $\mathrm{Z}$ goods \\
\hline \multicolumn{3}{|c|}{ Non-commodity Sector (M) } \\
\hline$\alpha_{M}$ & 0.4 & share of capital \\
\hline$\omega_{M *}$ & 1.817 & governs share of $\mathrm{M}$ goods \\
\hline
\end{tabular}


Table 1: Calibrated Parameters

\begin{tabular}{|c|c|c|}
\hline Parameter & Value & Description \\
\hline \multicolumn{3}{|c|}{ Import Sector (F) } \\
\hline$\omega_{F}$ & 0.621 & weights of $\mathrm{F}$ goods in tradable goods bundle \\
\hline \multicolumn{3}{|c|}{ Structural Shocks } \\
\hline$\rho_{R^{*}}$ & 0.98 & autocorrelation foreign interest rate shock \\
\hline$\rho_{\Pi *}$ & 0.52 & autocorrelation foreign inflation shock \\
\hline$\rho_{Y^{*}}$ & 0.65 & autocorrelation foreign output shock \\
\hline$\sigma_{R^{*}}$ & 0.001 & standard deviation foreign interest rate shock \\
\hline$\sigma_{\Pi^{*}}$ & 0.002 & standard deviation foreign inflation shock \\
\hline$\sigma_{Y^{*}}$ & 0.002 & standard deviation foreign output shock \\
\hline$\rho_{\psi}$ & 0.87 & autocorrelation risk premium shock \\
\hline$\sigma_{\psi}$ & 0.005 & standard deviation risk premium shock \\
\hline$\rho_{\xi}$ & 0.76 & autocorrelation preference shock \\
\hline$\sigma_{\xi}$ & 0.015 & standard deviation preference shock \\
\hline$\rho \Upsilon$ & 0.035 & autocorrelation investment shock \\
\hline$\sigma_{\Upsilon}$ & 0.066 & standard deviation investment shock \\
\hline$\rho_{z_{M}}$ & 0.93 & autocorrelation technology shock M sector \\
\hline$\rho_{z_{N}}$ & 0.99 & autocorrelation technology shock $\mathrm{N}$ sector \\
\hline$\rho_{z_{Z}}$ & 0.83 & autocorrelation technology shock Z sector \\
\hline$\sigma_{z_{M}}$ & 0.02 & standard deviation technology shock M sector \\
\hline$\sigma_{z_{N}}$ & 0.011 & standard deviation technology shock N sector \\
\hline$\sigma_{z_{Z}}$ & 0.065 & standard deviation technology shock \\
\hline
\end{tabular}


Table 2: Steady State Properties of the Model

Expenditure (percent of GDP)

Consumption

Private investment

Exports

Imports

Production (percent of GVA)

Non-tradable

Other tradable

Mining

Trade (percent of export)

Resource exports

Other

Employment (percent of total employment)

Non-tradable

Other tradable

Mining
Data(1994-2017) Model

$0.75 \quad 0.76$

$0.26 \quad 0.27$

$0.22 \quad 0.23$

$0.23 \quad 0.24$

$0.66 \quad 0.66$

$0.22 \quad 0.22$

$0.12 \quad 0.10$

$0.44 \quad 0.44$

$0.56 \quad 0.56$

$0.27 \quad 0.27$

$0.09 \quad 0.11$ 
Table 3: Estimated Parameters

\begin{tabular}{lll}
\hline Parameter & Value & Description \\
\hline$h$ & $0.93(0.024)$ & habit persistence \\
$\phi$ & $16.99(2.378)$ & labour supply elasticity \\
$\Phi_{K}$ & $3.09(0.226)$ & investment adjustment cost \\
$\theta_{N}$ & $0.92(0.016)$ & Calvo parameter Non-Traded Sector (N) \\
$\theta_{M}$ & $0.66(0.45)$ & Calvo parameter Non-Commodity Tradable Sector (M) \\
$\theta_{F}$ & $0.95(0.02)$ & Calvo parameter Import Sector (F) \\
$\theta_{Z}$ & $0.58(0.133)$ & Calvo parameter Commodity Sector (Z) \\
$\rho_{\sigma_{P}}$ & $0.62(0.043)$ & persistence of commodity price shock process \\
$\rho_{\sigma_{P}}$ & $0.93(0.037)$ & persistence of volatility shock process \\
$\sigma_{P_{Z}}$ & $0.02(0.005)$ & degree of mean volatility \\
$\kappa$ & $0.13(0.1)$ & degree of stochastic volatlity \\
\hline & &
\end{tabular}

Notes: This table reports the estimated parameters in Section 5 along with the standard errors in parentheses. 

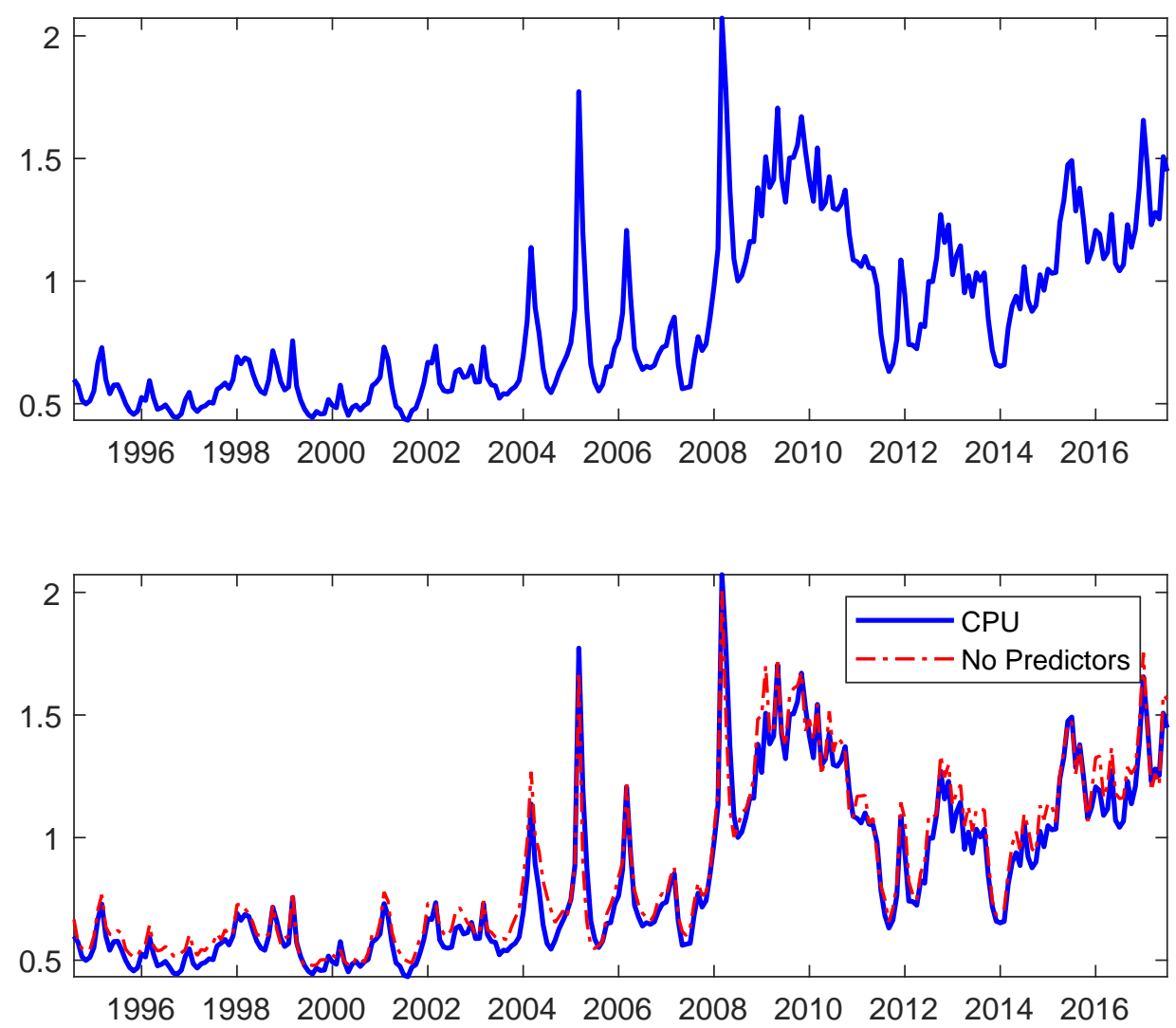

Figure 1: Commodity Price Uncertainty Index for Australia (CPU)

Notes: This monthly index plots the level of commodity uncertainty for Australia described in Section 2. 

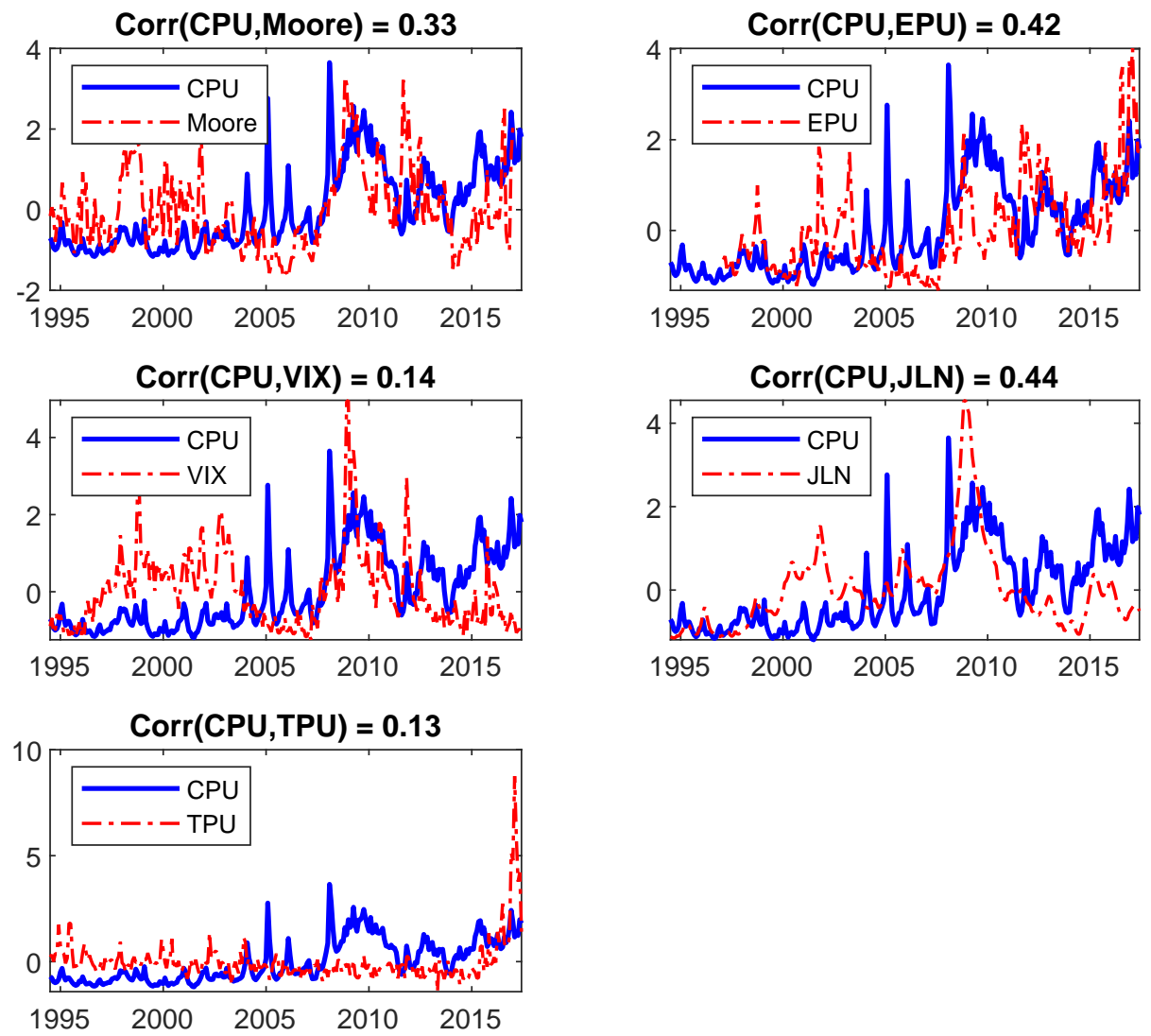

Figure 2: Correlation with Alternative Measures of Uncertainty

Notes: This monthly index compares the commodity price uncertainty index for Australia with a number of uncertainty indicies in the literature namely, the Economic Uncertainty Index for Australia constructed by Moore (2017); the Global Economic Policy Uncertainty index constructed by Baker et al. (2016), the CBOE Volatility Index (VIX), the Macroeconomic Uncertainty Index for the U.S constructed by Jurado et al. (2015) and the Trade Policy Uncertainty Index constructed by Caldara et al. (2020). All series are normalized to have means of zero and standard deviations of one. 

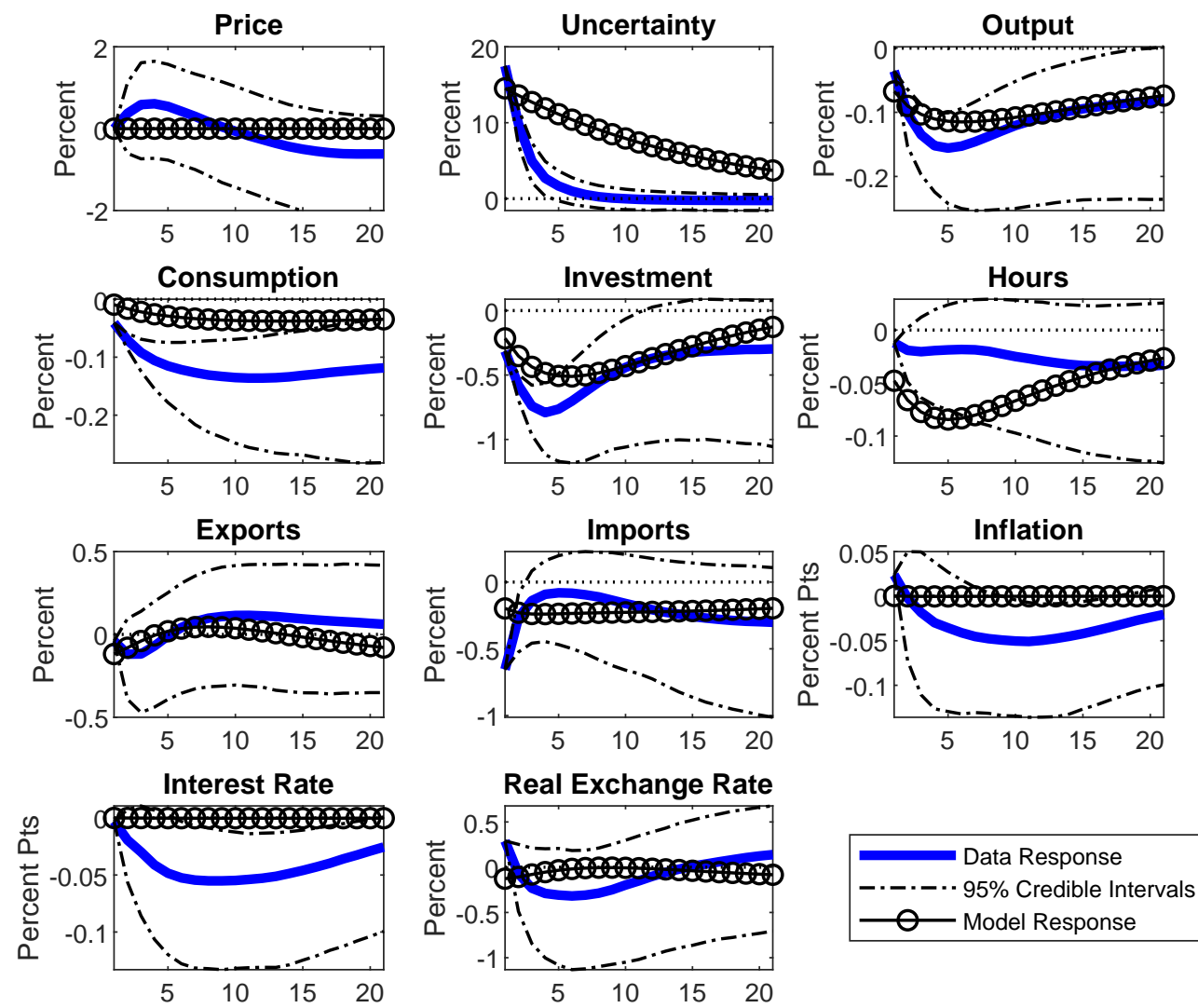

Figure 3: IRFs to a One-Standard Deviation Innovation CPU Shock

Notes: This figure shows the impulse response functions according to the VAR specification in Section 3. This also plots the DSGE model responses in Section 4. The dashed lines plot the $95 \%$ credible intervals. 

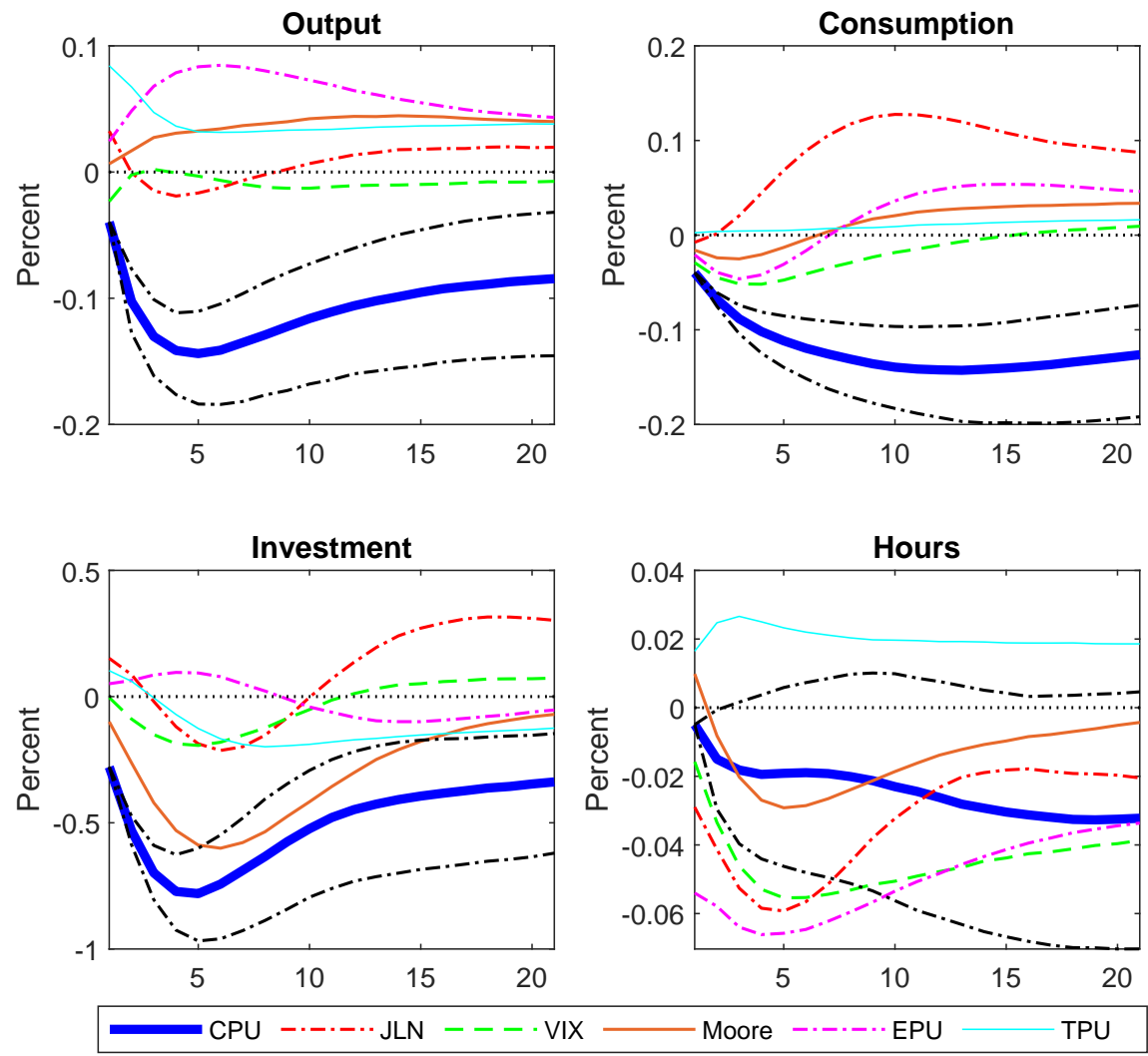

Figure 4: IRFs to a One-Standard Deviation Innovation CPU Shock - a Comparison

Notes: This figure shows the impulse response functions according to the VAR specification in Section 3 of CPU versus the Moore (2017) uncertainty index for Australia, the VIX, the Baker et al. (2016) global economic policy uncertainty index, the Jurado et al. (2015) macroeconomic uncertainty index for the U.S, and the trade policy uncertainty index (Caldara et al. (2020)). The dashed lines plot the $95 \%$ credible intervals. 

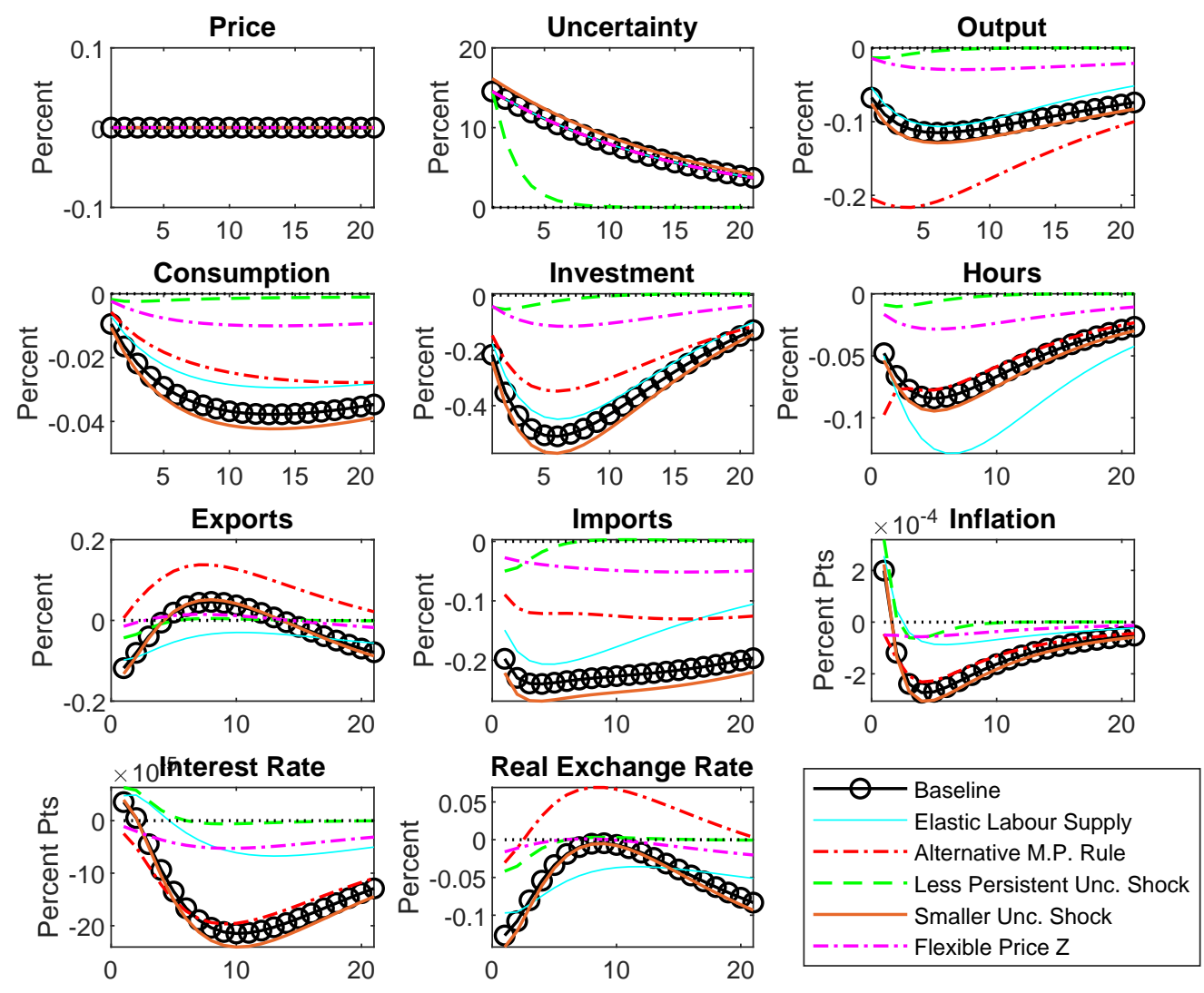

Figure 5: Aggregate Variables' Responses to a CPU shock

Notes: Each IRF is measured in terms of the percentage deviation from its steady state value. The shock is a one standard deviation increase in commodity price uncertainty. 

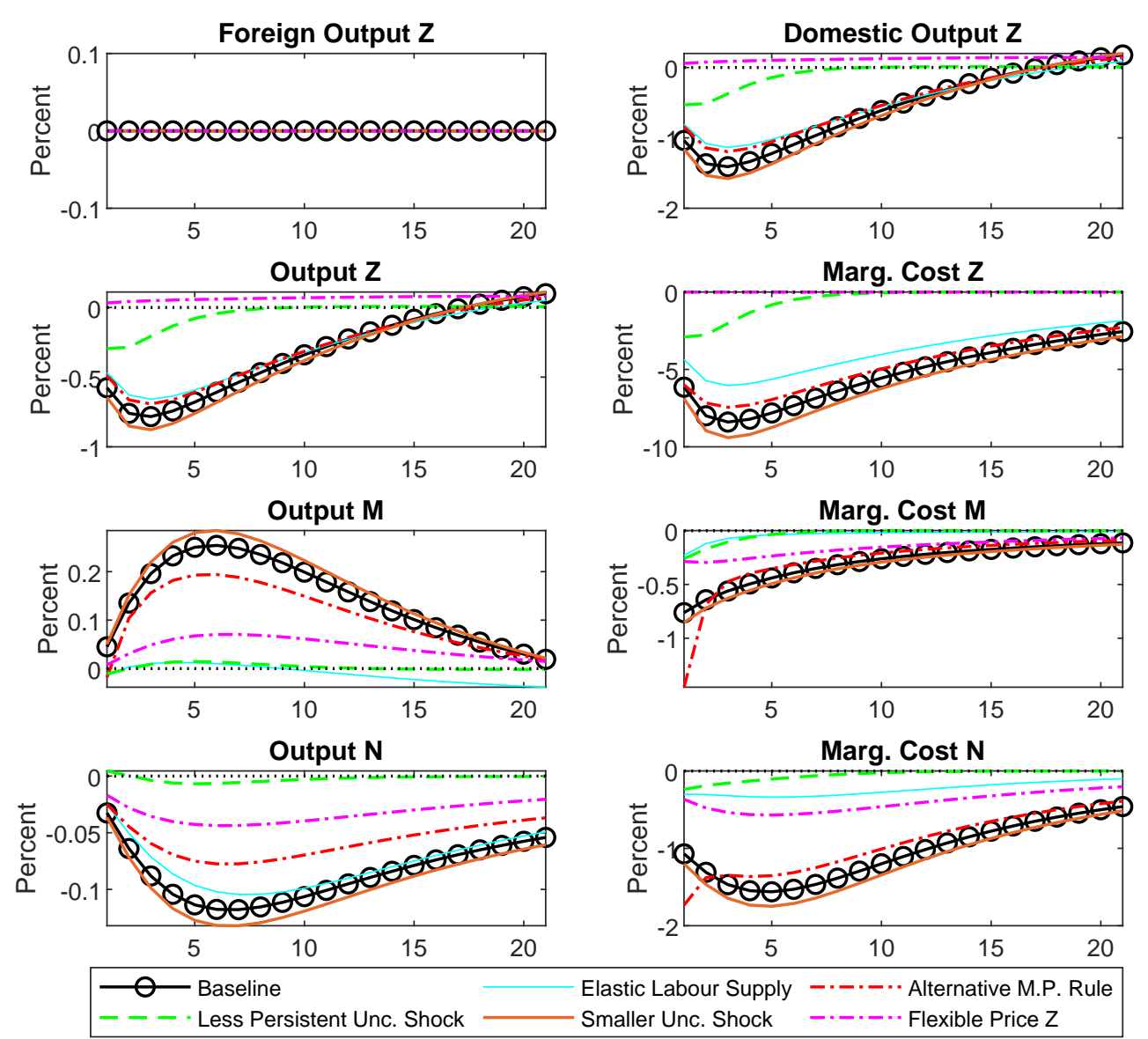

Figure 6: Sectoral Variables' Responses to a CPU Shock

Notes: Each IRF is measured in terms of the percentage deviation from its steady state value. The shock is a one standard deviation increase in commodity price uncertainty. 

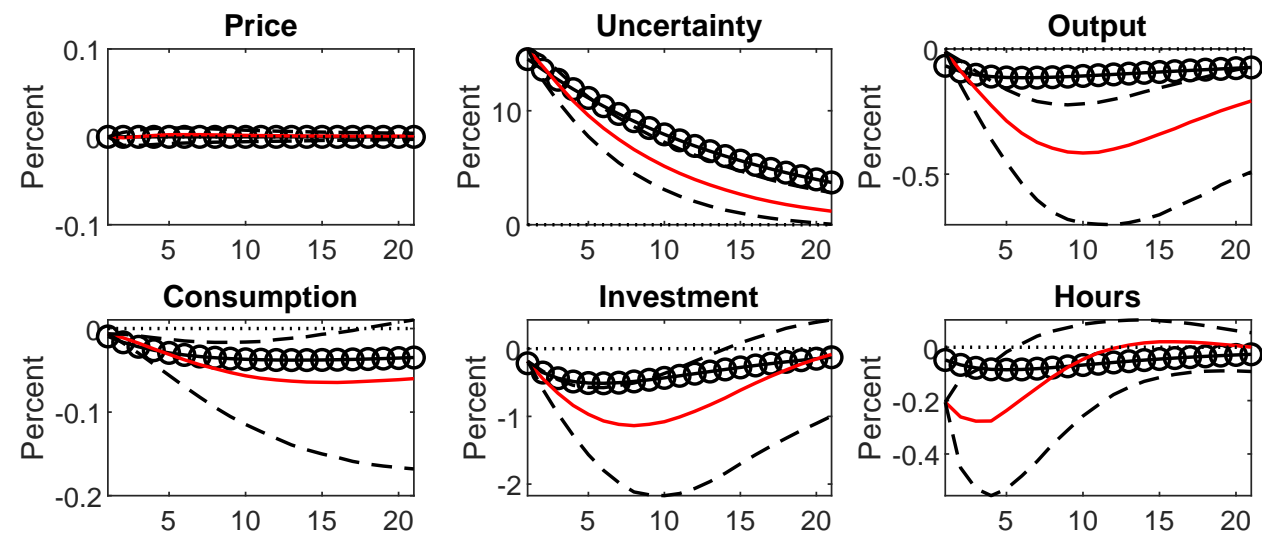

Hours
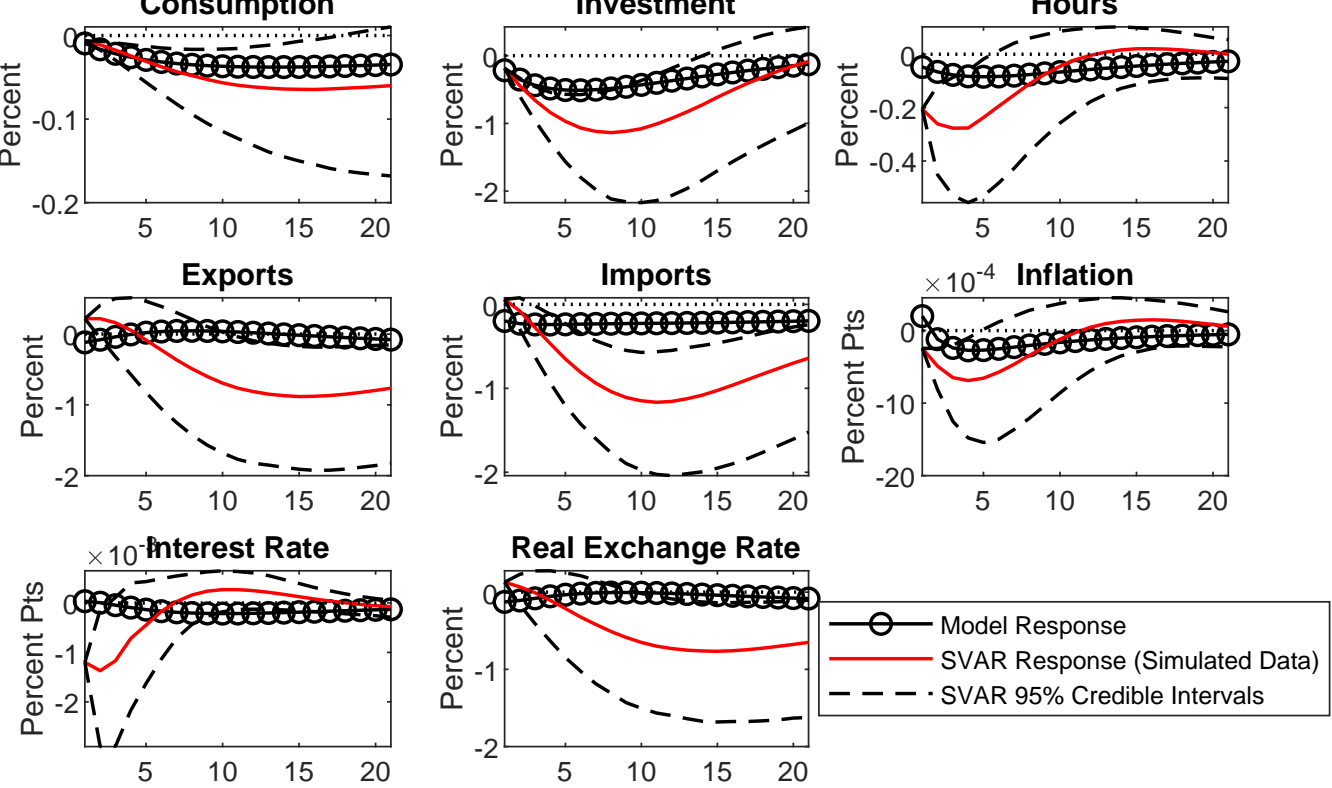

Figure 7: Structural VAR with Simulated Data from the DSGE Model 


\section{Appendix for "The Macroeconomic Effects of Commodity Price Uncertainty" by Trung Duc Tran NOT FOR PUBLICATION}

\section{Data Sources and Definitions}

GDP: Gross domestic product: Chain volume measures. Source: ABS Cat. 5206.0 Australian National Accounts: National Income, Expenditure and Product. Table 1. Key National Accounts Aggregates.

Consumption: Households; Final consumption expenditure. Source: ABS Cat. 5206.0 Australian National Accounts: National Income, Expenditure and Product. Table 2. Expenditure on Gross Domestic Product (GDP), Chain volume measures.

Investment: Private; Gross fixed capital formation. Source: ABS Cat. 5206.0 Australian National Accounts: National Income, Expenditure and Product. Table 2. Expenditure on Gross Domestic Product (GDP), Chain volume measures.

Export, Import: Exports of goods and services;Imports of goods and services. Source: ABS Cat. 5206.0 Australian National Accounts: National Income, Expenditure and Product. Table 2. Expenditure on Gross Domestic Product (GDP), Chain volume measures.

Sector definition: This paper follows Rayner et al. (2013) to consider the broad measure of the commodity sector that includes both direct activity in the commodity sector and commodity-related activity in other sectors. Non-traded sector includes the electricity, gas, water and waste industry, the construction industry, the retail trade industry, the information, media and telecommunications industry, the finance and insurance industry, the real estate industry, the professional services industry, the administrative services industry, the public administration industry, the education industry, the healthcare industry, the arts and recreation industry, the other services industry and ownership of dwellings. Non-commmodity sector includes the agriculture, forestry and fishing industry (excluding agriculture), the manufacturing industry, the transport industry, the wholesale trade industry, and the accommodation and food services industry.

Value-added: Commodity sector, non-commodity sector and non-traded sector value added. Source: ABS Cat. 5206.0 Australian National Accounts: National Income, Ex- 
penditure and Product Table 6. Gross Value Added by Industry, Chain volume measures

Employment: Source: ABS Cat. 6291.0.55.003 Labour Force, Australia, Detailed, Quarterly. Table 04. Employed persons by Industry division of main job (ANZSIC) Trend, Seasonally adjusted, and Original

Hours worked: Quarterly hours worked in all jobs. Source: ABS Cat. 6202.0 Labour Force, Australia. Table 21. Quarterly hours worked in all jobs by Market and Non-market sector - Seasonally adjusted

Cash rate: Quarterly average interbank overnight cash rate. Source: RBA Statistical Table F1.1 Interest Rates and Yields - Money Market.

Real exchange rate: Real trade-weighted exchange rate index. Source: RBA Statistical Table F15 Real Exchange Rate Measures.

Commodity export: Resource export volumes, seasonally adjusted and in chain volume terms. Source: RBA Statistical Table I1 International Trade and Balance of Payments

Non-commodity export: Non-resource export volumes are calculated as the difference between total export volumes and resource export volumes, with all data in seasonally adjusted and chain volume terms. Source: RBA Statistical Table I1 International Trade and Balance of Payments

Commodity export as percentage of total commodity export: This is calculated by selecting the commodities that are in the Top 25 Australian exports of goods and services. Gold and meats (excluding beef) are not included as the IMF Commodity Price does not have them. Source: DFAT Australia's goods and services by top 25 export

\section{The Construction of the CPU Index}

\section{Price Uncertainty for Each Major Commodity Exported by Aus- tralia}

Base metal and fuel make up a large proportion of total commodity exports in Australia as seen in Table A1. Iron ores and coal together are accountable for more than $60 \%$ of total commodity export value. Figure A1 plots rice uncertainty for each major commodity that is exported by Australia. 


\section{Examining the Role of Different Predictive Equation Specifica- tions in Capturing Uncertainty}

The forecasting equation in the paper is chosen due to the advantage of its having direct interpretation from each of the predictors. Instead of doing that, the set of predictors could be postulated by estimating an optimal number of principle components for all predictors according to the Bai and $\mathrm{Ng}$ (2002) criterion as in Jurado et al. (2015). Figure A2 compares the uncertainty plot for each group of commodity with the different predictive equation specification. I find that the results are consistent across different equation specifications.

\section{Examining the Role of Different Weighting Approach}

Instead of weighting individual uncertainty by using the export shares as in the baseline case, we can also:

1. Equally weight each individual series

2. Construct a common factor for each group of commodity uncertainty as the first principle component as in Jurado et al. (2015).

The results are quite consistent across different weighting methods as shown in Figure A3

\section{Addtional VAR results}

\section{Robustness Checks}

The results are robust to a number of additional sensitivity checks including lag sensitivity; the removal of commodity price; a different ordering of the variables in the VAR where uncertainty is placed last; the removal of the time trend. The robustness checks can be found in A4.

\section{The Effects of Different Types of Uncertainty shocks}

Figure A5 compares the effects of different types of uncertainty shocks on output, consumption, investment, hours-worked, exports, imports, the inflation rate, the cash rate 
and the real exchange rate.

\section{Addtional DSGE results}

\section{Robustness Checks of the Model-Based Support for Empirical Identification}

A timing restriction is imposed in the VAR analysis to identify CPU shocks. This ordering assumes that CPU shocks in the VAR model can have an immediate impact on other macroeconomic variables in the system, but other shocks do not affect uncertainty on impact. This section provides an assessment on whether such an empirical identification is supported by the DSGE model through employing a simulation exercise. 5000 observations are actually simulated. The first 1000 observations are dropped to eliminate any initial condition effects. The next 400 observations are kept and estimated; then contrasted to the estimation of 4000 observations to check whether there is any estimation gains that can be attained as the sample size becomes significantly larger. Figure A6 shows that the results are affected by the initial condition effects but not by the sample size. 
Table A1: Top Australian Commodity Exports as Percentage of Total Commodity Exports

\begin{tabular}{lccccccc}
\hline & 2012 & 2013 & 2014 & 2015 & 2016 & 2017 & Avg: 2012-2017 \\
\hline Iron ores & 0.36 & 0.42 & 0.39 & 0.34 & 0.35 & 0.34 & 0.37 \\
Coal & 0.27 & 0.24 & 0.23 & 0.25 & 0.28 & 0.30 & 0.26 \\
Natural gas & 0.09 & 0.09 & 0.11 & 0.11 & 0.12 & 0.14 & 0.11 \\
Aluminum & 0.06 & 0.06 & 0.06 & 0.08 & 0.06 & 0.06 & 0.06 \\
Beef & 0.03 & 0.03 & 0.05 & 0.06 & 0.05 & 0.04 & 0.04 \\
Wheat & 0.04 & 0.04 & 0.04 & 0.04 & 0.03 & 0.03 & 0.04 \\
Crude petroleum & 0.07 & 0.05 & 0.06 & 0.04 & 0.03 & 0.03 & 0.05 \\
Copper & 0.06 & 0.05 & 0.05 & 0.06 & 0.05 & 0.04 & 0.05 \\
Wool & 0.02 & 0.02 & 0.01 & 0.02 & 0.02 & 0.02 & 0.02 \\
\hline
\end{tabular}

Notes: This table separates commodity exports from Australia's Top 25 goods and services exports. 

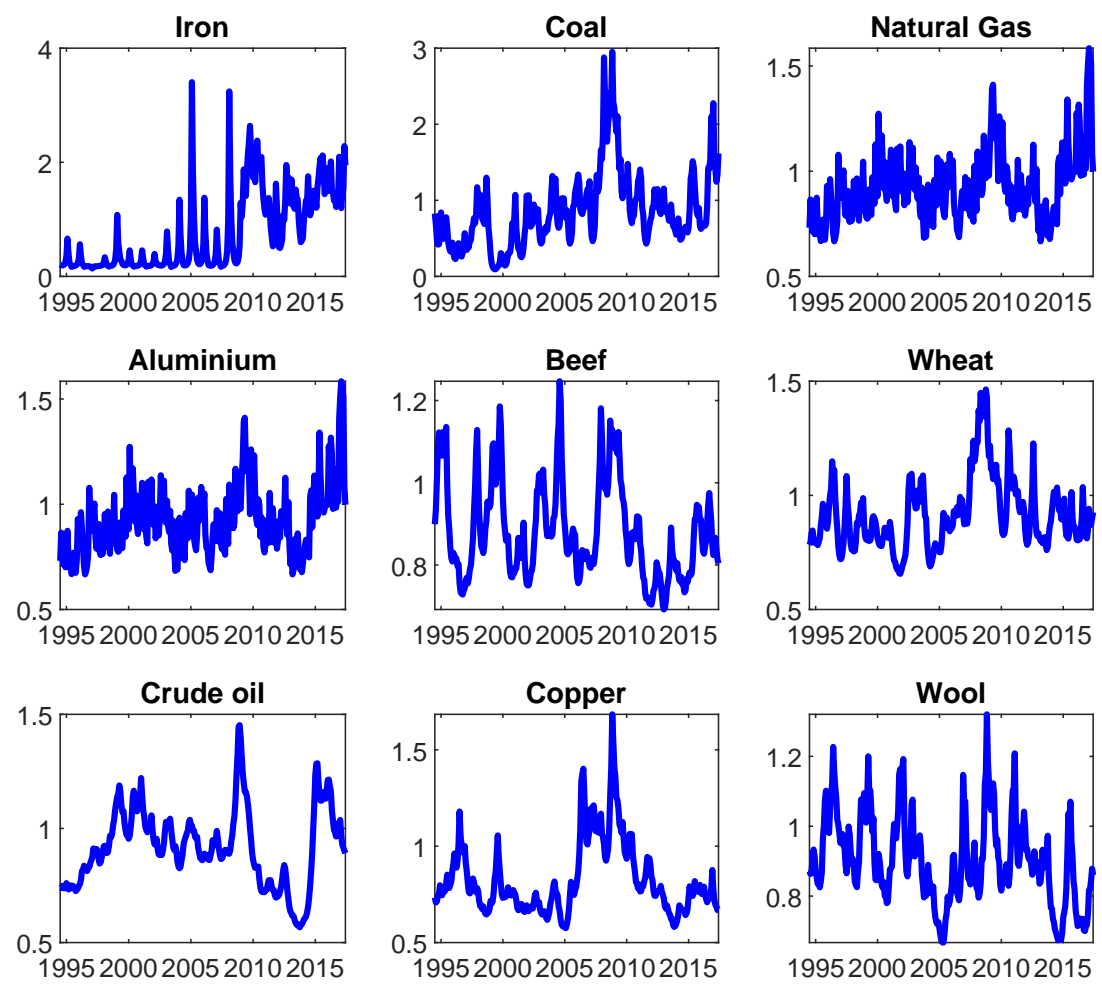

Figure A1: Uncertainty for Each Major Commodity Exported by Australia

Notes: This monthly index plots the level of price uncertainty for a number of commodity series. These commodity series actually make up the final commodity price uncertainty index for Australia. 


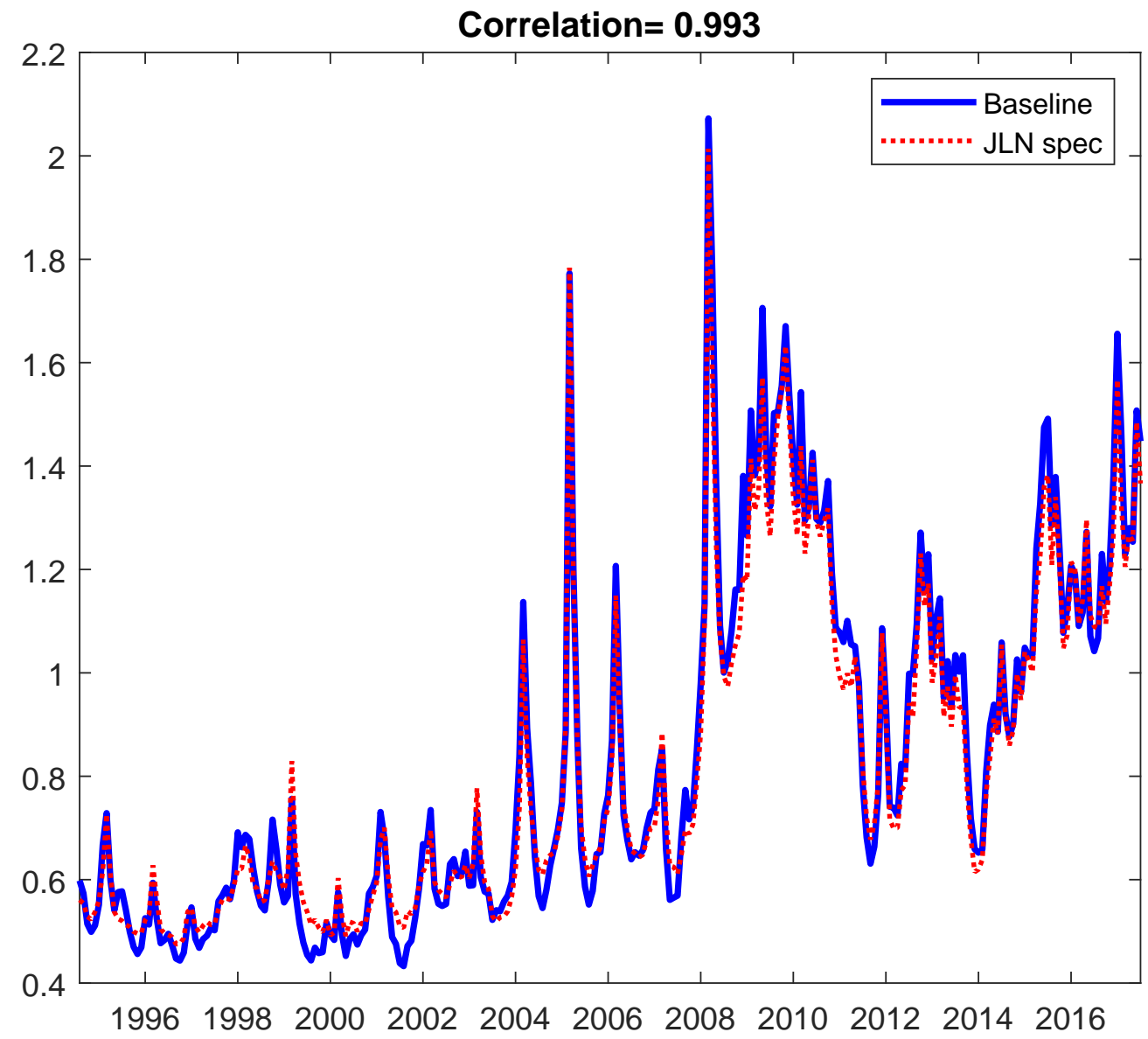

Figure A2: Commodity Price Uncertainty for Australia: Different Predictive Equation Specification 


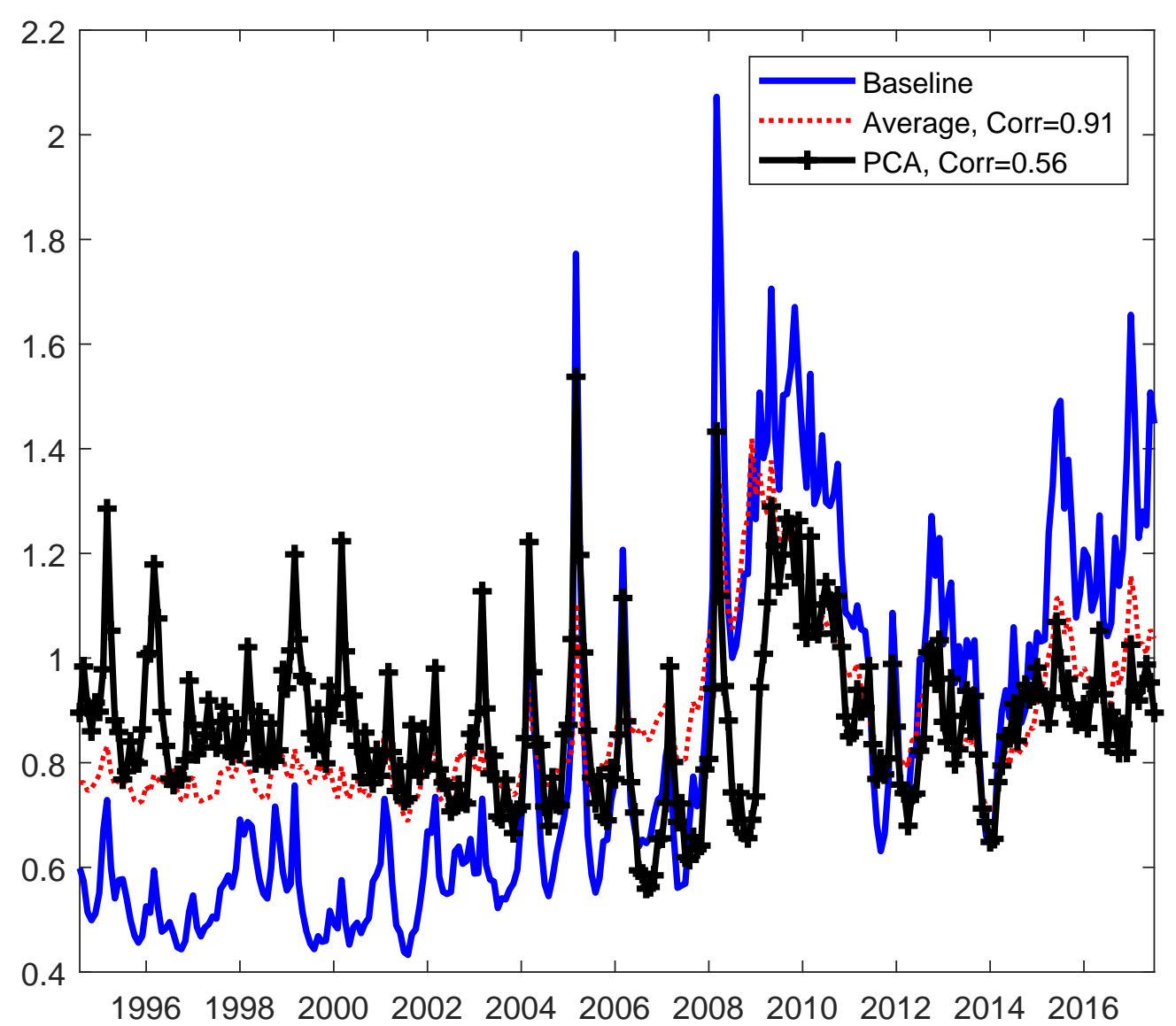

Figure A3: Commodity Price Uncertainty for Australia: Comparing to Average Uncertainty and Principle Component Uncertainty

Notes: This monthly index compares the baseline commodity price uncertainty index for Australia to the alternatives according to the method outlined in the Appendix. 

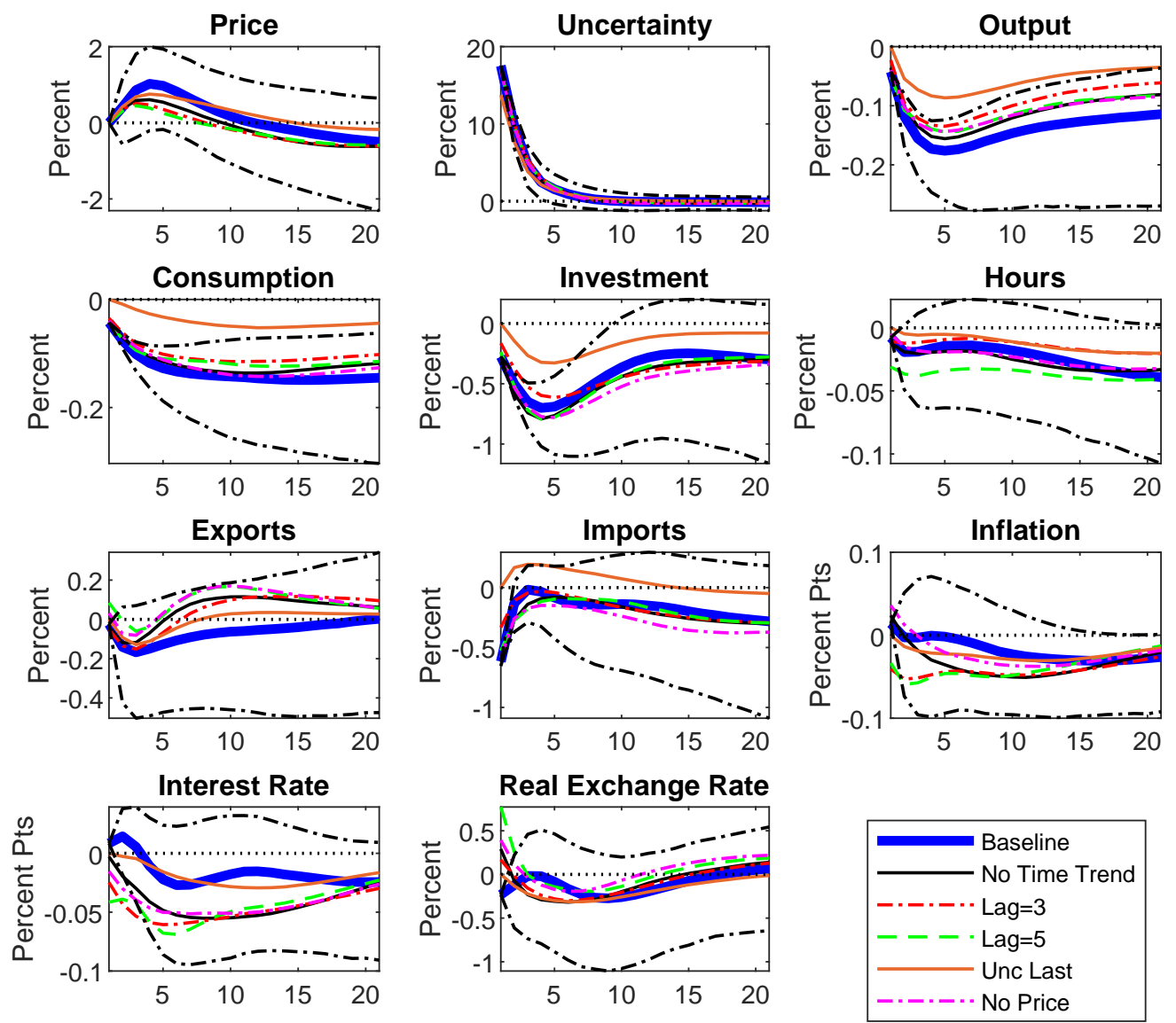

Figure A4: Robustness: IRFs to a One-Standard Deviation Innovation CPU Shock

Notes: This figure shows the impulse response functions according to the VAR specification along with several robustness checks including, a 3-lag VAR and a 4-lag VAR, a VAR without a linear time trend, a different ordering where uncertainty is placed last, and the removal of commodity prices from the VAR. The credible interval is $\pm 95 \%$. 

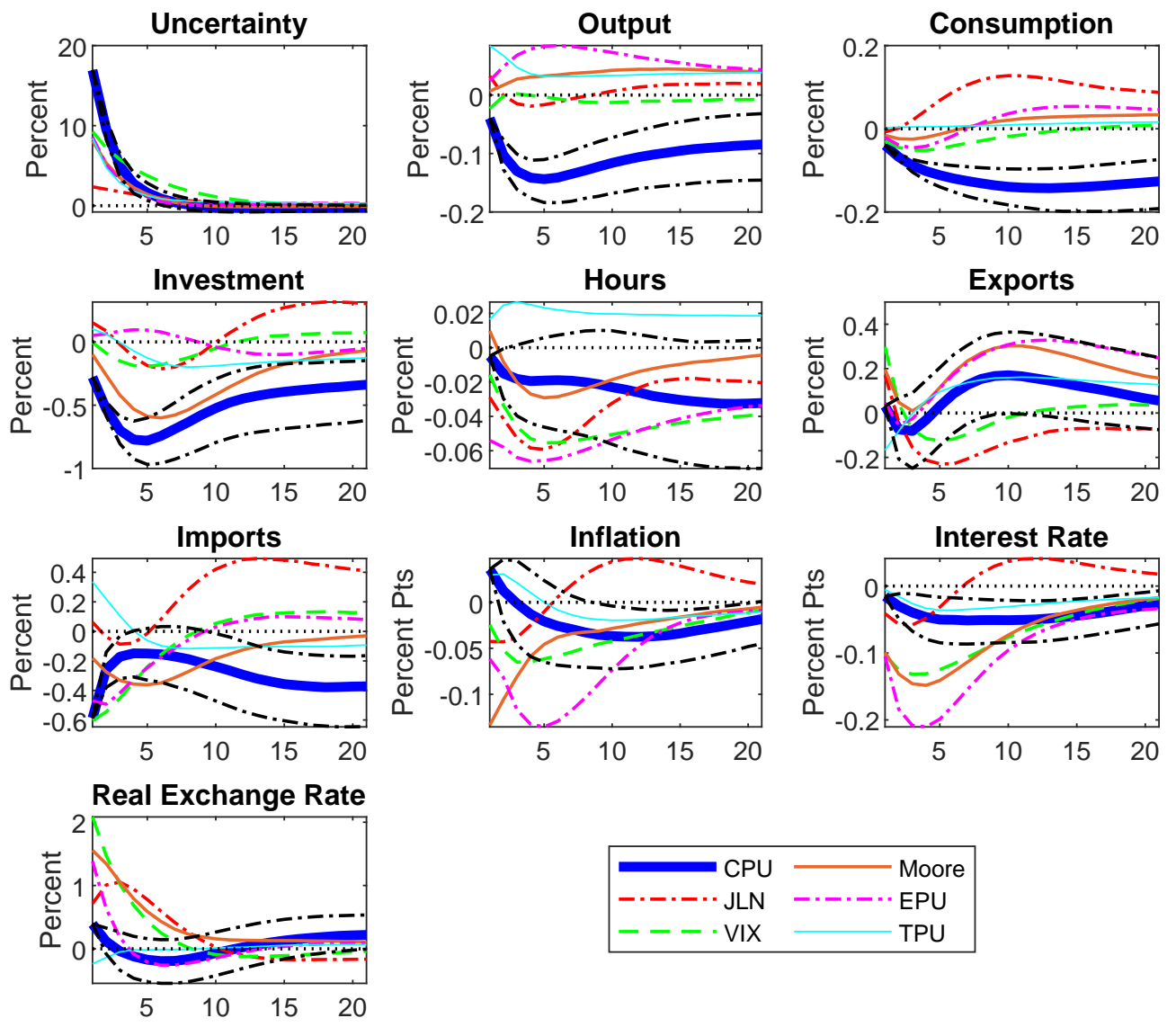

Figure A5: Robustness: IRFs to a One-Standard Deviation Innovation CPU Shock - a Comparison

Notes: This figure shows the impulse response functions according to the VAR specification of CPU versus Moore (2017) uncertainty index for Australia, the VIX, the Baker et al. (2016) global economic policy uncertainty index, the Jurado et al. (2015) macroeconomic uncertainty index for the U.S, and the trade policy uncertainty index (Caldara et al. (2020)). The dashed lines plot the $95 \%$ credible intervals. 

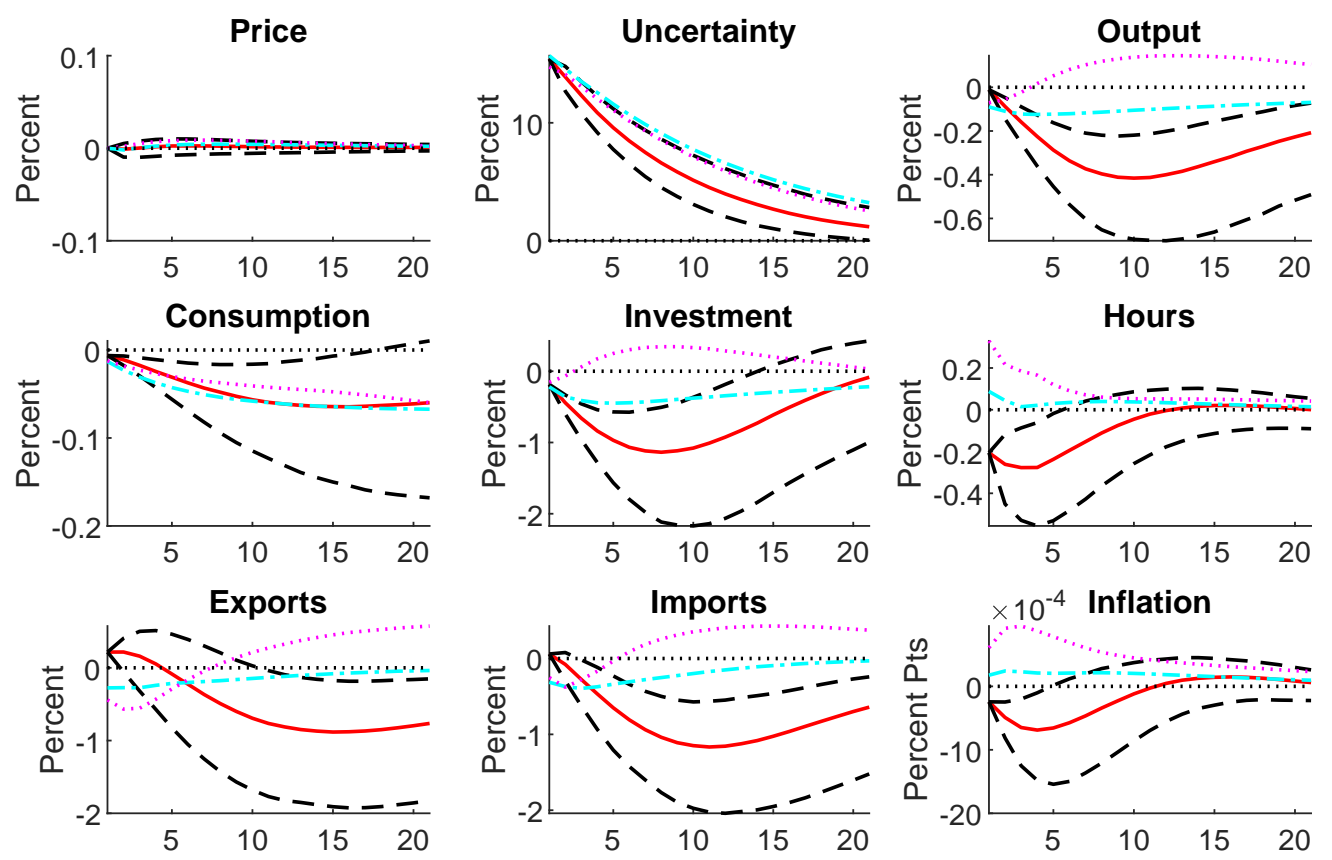

Imports
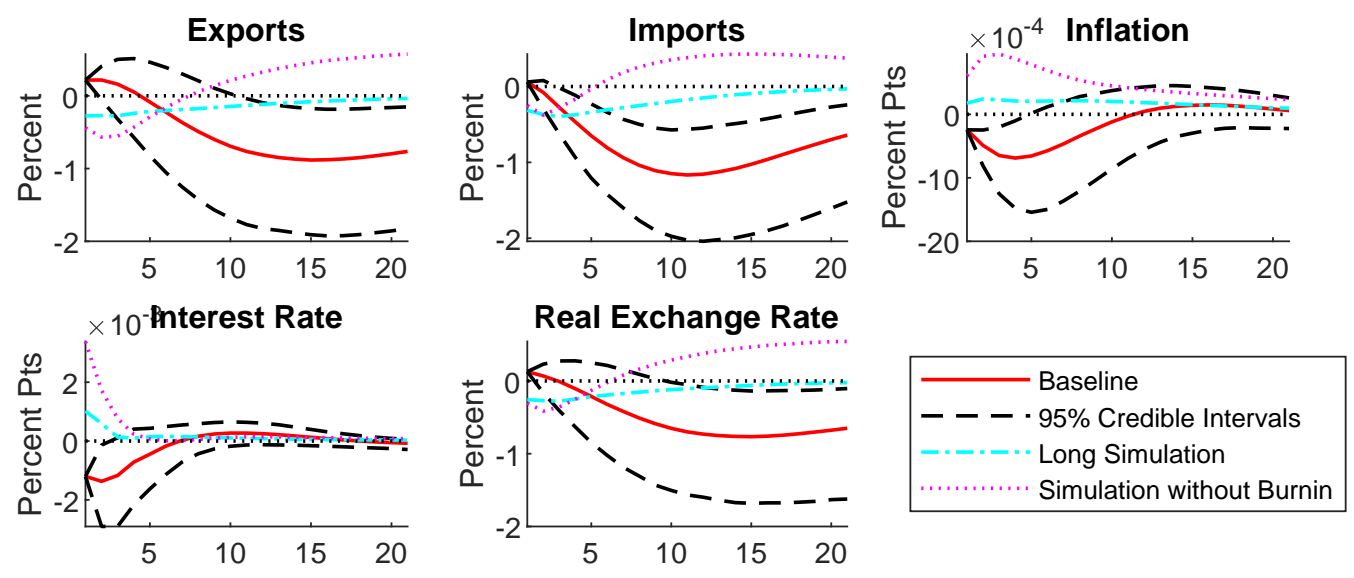

Figure A6: Robustness: Structural VAR with Simulated Data from the DSGE Model 


\section{References}

Bai, J. and Ng, S. (2002). Determining the number of factors in approximate factor models. Econometrica, 70(1):191-221.

Baker, S. R., Bloom, N., and Davis, S. J. (2016). Measuring economic policy uncertainty. The Quarterly Journal of Economics, 131(4):1593-1636.

Caldara, D., Iacoviello, M., Molligo, P., Prestipino, A., and Raffo, A. (2020). The economic effects of trade policy uncertainty. Journal of Monetary Economics, 109:38 59.

Jurado, K., Ludvigson, S. C., and Ng, S. (2015). Measuring uncertainty. American Economic Review, 105(3):1177-1216.

Moore, A. (2017). Measuring economic uncertainty and its effects. Economic Record, June:1-26.

Rayner, V., Bishop, J., et al. (2013). Industry dimensions of the resource boom: an input-output analysis. 